\title{
X-Band Dual-Polarization Radar Observations of Snow Growth Processes of a Severe Winter Storm: Case of 12 December 2013 in South Korea
}

\author{
S. AllabAKASH AND S. LiM \\ Korea Institute of Civil Engineering and Building Technology, Ilsan, South Korea \\ V. CHANDRASEKAR \\ Colorado State University, Fort Collins, Colorado \\ K. H. MIN \\ Kyungpook National University, Daegu, South Korea \\ J. CHOI \\ Chosun College of Science and Technology, Gwangju, South Korea \\ B. JANG \\ Korea Institute of Civil Engineering and Building Technology, Ilsan, South Korea
}

(Manuscript received 13 May 2018, in final form 10 April 2019)

\begin{abstract}
The characteristics of microphysical processes of a severe winter storm that occurred on the Korean Peninsula on 12 December 2013 was studied in this work for the first time via X-band dual-polarization weather radar observations. A new range-height indicator (RHI) scan-based quasi-vertical profile methodology, in which polarimetric radar variables were averaged at each height of the RHI scan, was introduced to investigate the snow microphysics, and the obtained polarimetric radar signatures served as fingerprints of the dendritic growth, aggregation, and riming processes. Enhanced differential reflectivity $\left(Z_{\mathrm{dr}}\right)$ and specific differential phase shift $\left(K_{\mathrm{dp}}\right)$ bands were detected near the $-15^{\circ} \mathrm{C}$ isotherm, which signified the growth of dendrites or platelike crystals. The observed correlation between the increases in the reflectivity factor at horizontal polarization $Z_{\mathrm{h}}$ and copolar correlation coefficient $\rho_{\mathrm{hv}}$ and the decreases in $Z_{\mathrm{dr}}$ and $K_{\mathrm{dp}}$ magnitudes at lower heights suggested the occurrence of the aggregation process. The combination of high $Z_{\mathrm{h}}$ and low $Z_{\mathrm{dr}}$ values with turbulent atmospheric conditions observed at the ground level indicated the occurrence of the riming process. In addition, the negative $K_{\mathrm{dp}}$ and $Z_{\mathrm{dr}}$ values combined with high $Z_{\mathrm{h}}$ and $\rho_{\mathrm{hv}}$ magnitudes (observed near the end of the snow event) indicated the formation of graupel particles. The polarimetric radar signatures obtained for the snow growth processes were evident from ground observations and agreed well with the results of the Weather Research and Forecasting Model and Modern-Era Retrospective Analysis for Research and Applications data. Furthermore, the spatial variability of $Z_{\mathrm{h}}$ methodology was implemented to describe both aggregates and rimed ice particles.
\end{abstract}

\section{Introduction}

Winter storms produce high socioeconomic impact on human lives and property. The heavy snowfall occurring during a winter storm is a serious threat to

Corresponding author: S. Lim, slim@kict.re.kr transportation (especially aviation) and other related services. Snow growth processes affect the surface precipitation rate, which may have significant impact on the surface transportation (Juga et al. 2012) and agricultural activities. Therefore, monitoring and nowcasting of winter storms are important to provide early warnings. The proper interpretation of 
dual-polarization radar data plays a crucial role in describing the characteristics of the winter storm and making accurate predictions. Nevertheless, the latter remains a difficult task because of the uncertainty in interpreting the cloud composition and microphysics of snow growth processes (Schrom et al. 2015).

Ice particles can grow through the vapor deposition, aggregation, and riming processes (Houze 2014; Magono and Lee 1966; Pruppacher and Klett 1997; Wallace and Hobbs 2006). Further, ice multiplication is also an important process for ice growth in clouds (Hallett and Mossop 1974). Several researchers (Wolde and Vali 2001; Kennedy and Rutledge 2011; Andrić et al. 2013; Bechini et al. 2013; Griffin et al. 2014; Moisseev et al. 2015; Schrom et al. 2015; Kumjian et al. 2016; Kumjian and Lombardo 2017; Griffin et al. 2018) observed very interesting polarimetric radar signatures of the enhanced differential reflectivity $\left(Z_{\mathrm{dr}}\right)$ and specific differential phase $\left(K_{\mathrm{dp}}\right)$ layers located above the melting layer, which were related to the growth of dendrites and platelike crystals. Kennedy and Rutledge (2011) found pronounced $Z_{\mathrm{dr}}$ and $K_{\mathrm{dp}}$ signatures near the $-15^{\circ} \mathrm{C}$ isotherm by conducting S-band radar observations during four different winter storm events. The authors also performed electromagnetic scattering simulations to describe the polarimetric radar signatures obtained by dendritic ice crystals. Bechini et al. (2013) conducted further analysis of the bands of high $K_{\mathrm{dp}}$ and $Z_{\mathrm{dr}}$ observed for stratiform precipitation events. They performed T-matrix electromagnetic scattering simulations at the C-band and X-band wavelengths to support the conclusion that the high values of $K_{\mathrm{dp}}$ aloft strongly correlated with heavy ground precipitation that was drawn by Kennedy and Rutledge in 2011. In another study, Andrić et al. (2013) observed enhanced layers of $Z_{\mathrm{dr}}$ and $K_{\mathrm{dp}}$ associated with low values of the copolar correlation coefficient $\rho_{\mathrm{hv}}$, which appeared as isolated pockets during a winter storm. The enhanced signatures were explained using a one-dimensional microphysical model incorporating the ice initiation, vapor deposition, and aggregation processes. They concluded that the proposed model roughly reproduced both the profile and magnitudes of the reflectivity factor at horizontal polarization $Z_{\mathrm{h}}$ and $\rho_{\mathrm{hv}}$ as well as the correct shapes (but not the magnitudes) of the $Z_{\mathrm{dr}}$ and $K_{\mathrm{dp}}$ bands. The authors also reported that some important microphysical processes affecting the observed signatures, such as secondary ice production, were not included into the model. In another context, Moisseev et al. (2015) explored the relationship between the "seeder-feeder" process and the values of $K_{\mathrm{dp}}$ and $Z_{\mathrm{dr}}$. Strong bands of $Z_{\mathrm{dr}}$ without perceptible $K_{\mathrm{dp}}$ signatures were produced by the ice crystals grown by vapor deposition at low particle concentrations, which explained the existence of a vertical offset between the $Z_{\mathrm{dr}}$ and $K_{\mathrm{dp}}$ bands. Further, the enhanced $K_{\mathrm{dp}}$ bands indicated the onset of snow aggregation. Recently, Kumjian and Lombardo (2017) elucidated the mechanism of the seeder-feeder processes occurred during the northeastern U.S. costal winter storms. In their study, it was documented that the strong $K_{\mathrm{dp}}$ bands observed near the $-15^{\circ} \mathrm{C}$ isotherm indicated the presence of large concentrations of planar crystals, which suggested highly efficient snow aggregation. The authors also concluded that the enhanced $Z_{\mathrm{dr}}$ signature with low $K_{\mathrm{dp}}$ values denoted the start of the planar crystal growth process. Temperature is also an important parameter of winter storms that influences the snow growth mechanism (Wallace and Hobbs 2006; Griffin et al. 2018; Houze 2014; Dolan and Rutledge 2009). Schneebeli et al. (2013) characterized the ice/snow properties by studying the variabilities of $Z_{\mathrm{dr}}$ and $K_{\mathrm{dp}}$ with temperature. They observed the formation of pristine ice crystals at temperatures below $-25^{\circ} \mathrm{C}$ (high altitudes), as indicated by the increases in these two parameters. The dendrites formed in the temperature range from $-20^{\circ}$ to $-15^{\circ} \mathrm{C}$ were signified by the enhancement of the corresponding $Z_{\mathrm{dr}}$ bands. Finally, aggregates were observed at temperatures above $-15^{\circ} \mathrm{C}$ (low altitudes), as indicated by the increase in $Z_{\mathrm{h}}$ and decrease in $Z_{\mathrm{dr}}$.

During heavy riming, ice particles may lose their original shape and form rimed particles (graupel). Generally, graupel particles exhibit conical, hexagonal, and lump shapes (Knight and Knight 1973; List and Schemenauer 1971; Locatelli and Hobbs 1974; Magono and Lee 1966). Lump and hexagonal graupel particles are produced at near zero or small positive $Z_{\mathrm{dr}}$ and $K_{\mathrm{dp}}$ values (Aydin and Seliga 1984; Carey and Rutledge 2000; Vivekanandan et al. 1999). Knight and Knight (1973) provided a detailed description of the formation and growth of conical graupel particles, which exhibited low/negative $Z_{\mathrm{dr}}$ and negative $K_{\mathrm{dp}}$ polarimetric signatures because of their vertical orientations and small apex angles (Aydin and Seliga 1984; Evaristo et al. 2013; Homeyer and Kumjian 2015; Bringi et al. 2017). Oue et al. (2015) reported that prolate ice particles were characterized by negative $K_{\mathrm{dp}}$ and $Z_{\mathrm{dr}}$ values; conversely, positive $K_{\mathrm{dp}}$ and $Z_{\mathrm{dr}}$ magnitudes corresponded to large isometric or slightly oblate ice particles. Bringi et al. (2017) described the properties of graupel particles using the data obtained with an S-band polarimetric radar, a 
two-dimensional video disdrometer (Schönhuber et al. 2008), and a multiangle snowflake camera (Garrett et al. 2012). The shape, orientations, and characteristics of graupel were determined via microwave backscattering calculations.

It is well known that rimed ice particles are denser and heavier and have higher terminal fall velocities than other ice particles (aggregates, dendrites, and pristine ones). Pristine ice crystals exhibit fall velocities less than $0.6 \mathrm{~m} \mathrm{~s}^{-1}$, while aggregates of dendrites and densely rimed particles have fall velocities in the range of $0.7-1.5 \mathrm{~m} \mathrm{~s}^{-1}$ (Locatelli and Hobbs 1974; Pruppacher and Klett 1997). The fall velocities above $1 \mathrm{~m} \mathrm{~s}^{-1}$ correspond to either aggregates or rimed particles. In some cases, it is difficult to classify the aggregation and riming processes according to vertical velocities $W$. Further, polarimetric radar signatures are not distinctive enough to differentiate between aggregates and rimed ice particles; instead, the spatial variability of $Z_{\mathrm{h}}(\mathrm{SVZ})$ factor related to particle size sorting and proportional to their fall velocity can be used for this purpose (Lim et al. 2013). The authors found that the rimed ice particles exhibited high $Z_{\mathrm{h}}$ values with large variabilities of $Z_{\mathrm{h}}$ as compared to those of aggregates. Moisseev et al. (2009) also showed that the smoothness of the reflectivity vertical profile of ice particles depended on their type. They reported that at lower heights, the large difference between $\max \left(Z_{\mathrm{h}}\right)$ and $\min \left(Z_{\mathrm{h}}\right)$ indicated rimed (dense) particles, while the opposite was true for aggregates.

Multiple research studies have been conducted to investigate the snow growth processes and ice particle habits (dendrites, aggregates, rimed particles, and graupel) in various regions of the world (Moisseev et al. 2015; Grazioli et al. 2015; Kouketsu et al. 2015; Oue et al. 2016; Bringi et al. 2017; Griffin et al. 2018). The topography of South Korea significantly differs from those of other countries. About $70 \%$ of its land is mountainous, especially in the northern and eastern parts. The eastern, western, and southern borders of South Korea are surrounded by the East Sea, Yellow Sea, and East China Sea, respectively. During winter, strong jet streams and orographic forcing can cause heavy snowfalls in this region. In the majority of studies conducted over different regions of South Korea, the snow growth processes were described by model-based scattering simulations. In this work, we cross validated the observed ice particle habits via the inferences of the Weather Research and Forecasting (WRF) Model (version 3.5.1), Modern-Era Retrospective Analysis for Research and Applications (MERRA) measurements, and ground observations.
Usually, winter storms in Korea do not produce graupel or heavy riming. The studied case represents an unusual/rare snowstorm event, during which large aggregates as well as heavily rimed and graupel particles were formed. No previous studies were conducted in the Korean Peninsula to describe the evolution of winter storms or variability of ice particles via dualpolarization radar measurements. Hence, this particular winter storm was investigated for the first time using high-spatiotemporal-resolution X-band polarimetric radar signatures. A new range-height indicator (RHI) scan-based quasi-vertical profile (R-QVP) methodology was utilized to determine $Z_{\mathrm{h}}$, $Z_{\mathrm{dr}}, K_{\mathrm{dp}}, \rho_{\mathrm{hv}}$, and spectrum width (SW) values and achieve a better understanding of the internal structure and evolution of the ice microphysical processes. The relation between the enhanced polarimetric radar signatures (such as large $Z_{\mathrm{dr}}$ and $K_{\mathrm{dp}}$ aloft values and high $Z_{\mathrm{h}}$ at lower heights) and the heavy snowfall on the ground was also established. At the end of the event, the negative $K_{\mathrm{dp}}$ and $Z_{\mathrm{dr}}$ magnitudes associated with high $Z_{\mathrm{h}}$ and $\rho_{\mathrm{hv}}$ in convective snow cells were examined. Additionally, the R-QVP method was applied to SVZ to distinguish between the aggregates and rimed ice particles.

This paper is organized as follows. Section 2 describes the R-QVP methodology for polarimetric variables. Observational data and synoptic conditions of the event are provided in section 3. The microphysics of the snow growth processes occurred during the winter storm on 12 December 2013 is interpreted in section 4 using X-band polarimetric radar signatures. Analysis of the entire snowfall event is conducted in section 5 using R-QVP vertical profiles. Finally, a summary and the conclusions of this study are presented in section 6 .

\section{R-QVP methodology}

Ryzhkov et al. (2016) explored a new QVP method for polarimetric radar variables to elucidate the vertical and temporal evolutions of ice microphysical processes. In this method, the data of plan position indicator (PPI) scans are azimuthally averaged over $360^{\circ}$ at a high fixed elevation angle $\left(>10^{\circ}\right)$ for each time step. In our study, the PPI data recorded at only $5^{\circ}$ and $6^{\circ}$ elevation angles were utilized, while $10 \mathrm{RHI}$ scans per volume were performed at fixed azimuthal angles from $0^{\circ}$ to $360^{\circ}$ and temporal resolution of 5 min (see Fig. 1). Therefore, we introduce a similar strategy exploiting RHI scans. A so-called R-QVP technique was used to calculate noise-reduced radar variables by the elevation-wise averaging of the 
Hybrid scan : 1 PPI / 1 min, 2 RHIs / 1 min
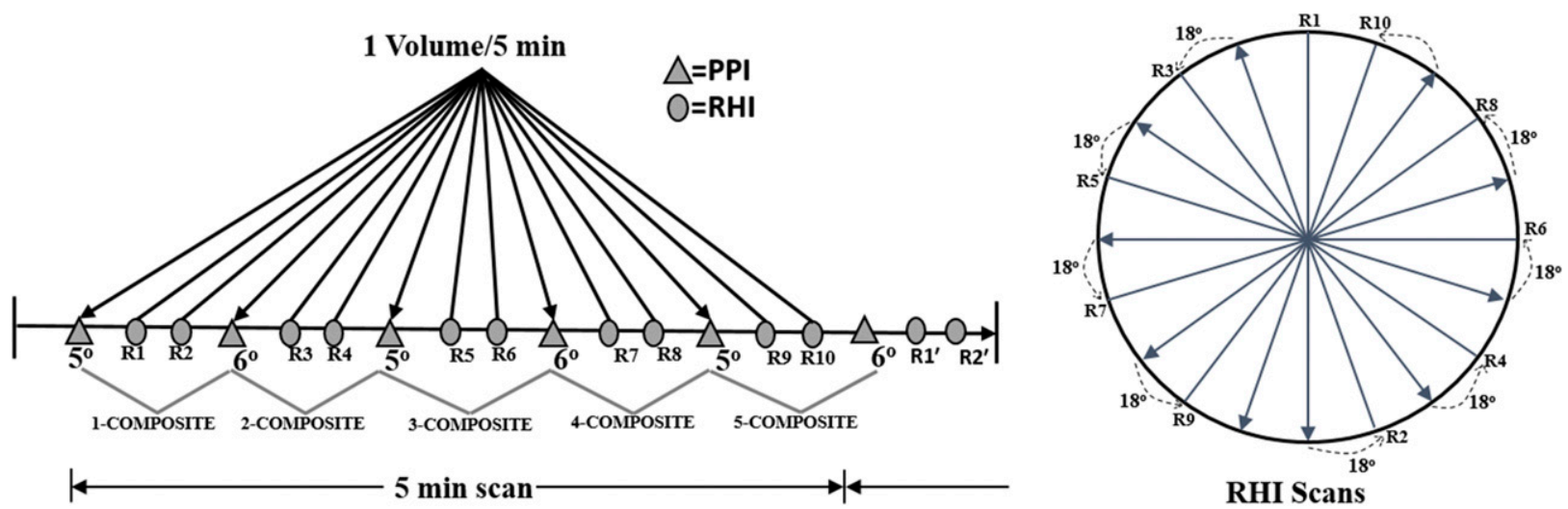

FIG. 1. KICT radar scanning strategy $($ composite $=$ PPI + RHI).

RHI data obtained at a fixed azimuth for each time step and transform the range coordinate into height. This procedure smoothed the vertical profiles and mitigated the errors of the radar variables. The data points considered for averaging were above the thresholds $\rho_{\mathrm{hv}}>0.7$ and $Z_{\mathrm{h}}>-2 \mathrm{~dB} Z$, while the radial gates that contained no data were not included into the averaging process. Further, a 250-m vertical resolution (obtained by converting the range coordinate into height) and a window of 6$20 \mathrm{~km}$ along the range axis were used. Figure 2 describes the utilized averaging procedure. Here, an R-QVP was constructed for the entire event as the time-height representation with a temporal resolution of $5 \mathrm{~min}$ and a height resolution of $250 \mathrm{~m}$. To minimize the radar beam broadening and ground clutter effects, the utilized range/distance was less than $20 \mathrm{~km}$, and the elevation angles ranged between $5^{\circ}$ and $45^{\circ}$ (Ryzhkov et al. 2016; Griffin et al. 2018; Kumjian et al. 2016). The magnitudes of $Z_{\mathrm{dr}}$ and $K_{\mathrm{dp}}$ decrease significantly at high elevation angles (Bringi and Chandrasekar 2001; Ryzhkov et al. 2016). Therefore, like in Ryzhkov et al. (2016) and Griffin et al. (2018), we use the following theoretical dependencies of the $Z_{\mathrm{dr}}$ and $K_{\mathrm{dp}}$ equivalent values on the high elevation angles $\left(>30^{\circ}\right)$ for oblate spheroidal hydrometeors:

$$
\begin{aligned}
& Z_{\mathrm{dr}}(\theta) \approx \frac{Z_{\mathrm{dr}}(0)}{\left[Z_{\mathrm{dr}}^{1 / 2}(0) \sin ^{2} \theta+\cos ^{2} \theta\right]^{2}}, \\
& K_{\mathrm{dp}}(\theta) \approx K_{\mathrm{dp}}(0) \cos ^{2} \theta .
\end{aligned}
$$

In Eq. (1), $Z_{\mathrm{dr}}(0)$ and $Z_{\mathrm{dr}}(\theta)$ are the linear-scale differential reflectivities at elevation angles $0^{\circ}$ and $\theta$, respectively. The $K_{\mathrm{dp}}$ value was derived from the differential phase $\Phi_{\mathrm{dp}}$ using the algorithm proposed by Wang and Chandrasekar (2009). The studied winter storm was a pure snow event; therefore, its $\Phi_{\mathrm{dp}}$ was not affected by the backscatter differential phase (Griffin et al. 2018).

\section{Observational data and synoptic overview}

a. X-band dual-polarization radar, MERRA, and WRF datasets

The observational data for this study were collected on 12 December 2013 during a severe winter storm using the Korea Institute of Civil Engineering and Building Technology X-band dual-polarization radar (referred to as the KICT radar). It was located in the Goyang Province $\left(37.6759^{\circ} \mathrm{N}, 126.7478^{\circ} \mathrm{E}\right)$, approximately $20.6 \mathrm{~km}$ northwest of Seoul, South Korea (Fig. 3). The radar provides high-spatial- and hightemporal-resolution data with an operational frequency

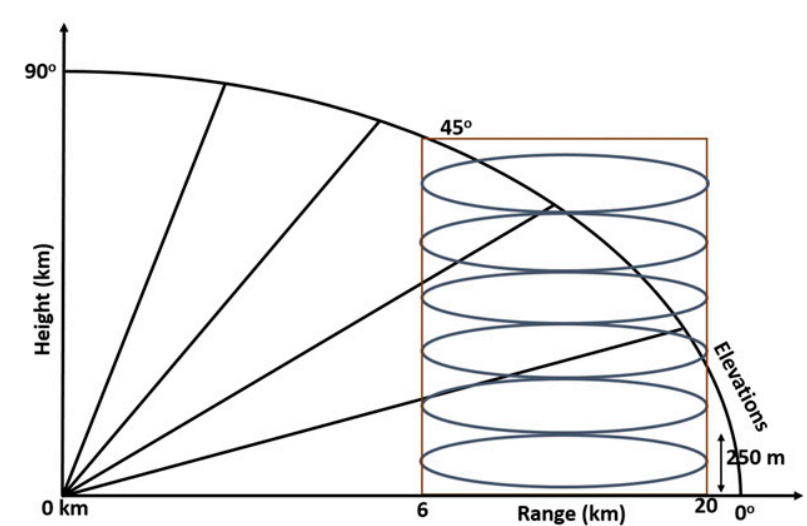

FIG. 2. Schematic illustrating the elevation-wise averaging strategy to construct R-QVPs. 


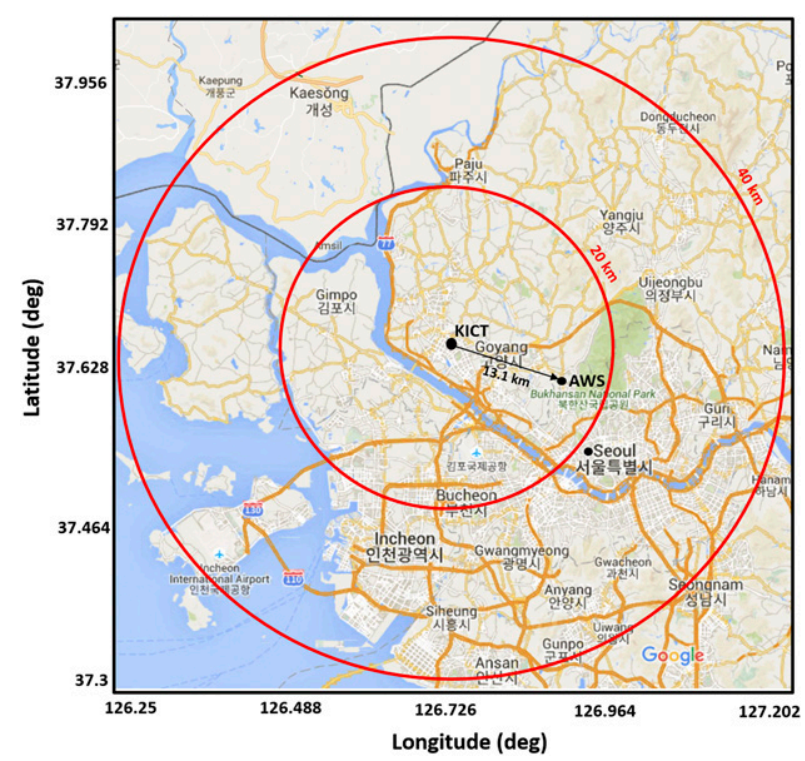

FIG. 3. Location of the KICT dual-polarization radar in South Korea and its coverage range circles with diameters of 20 and $40 \mathrm{~km}$.

of $9.41 \mathrm{GHz}$ and covers a range of $40 \mathrm{~km}$. It operated in a dual-polarization mode, which was also known as the simultaneous transmit and receive mode (STAR). The scan schedule encompasses 6 PPI and 10 hemispheric (with elevation angles of $0^{\circ}-180^{\circ}$ ) RHI scans every $5 \mathrm{~min}$. Over the duration of the winter storm event, the quasi-horizontal (PPI) data collection was performed by alternating between the elevation angles of $5^{\circ}$ and $6^{\circ}$ every minute at a range resolution of $60 \mathrm{~m}$. RHI scans were conducted at $18^{\circ}$ azimuth intervals. The main specifications of the KICT radar system and description of the utilized scanning strategy are provided in Table 1 and Fig. 1, respectively. The data collected by the KICT radar included the bias/error correction, attenuation correction for rain (performed by taking into account $\Phi_{\mathrm{dp}}$ ), data quality check (Scarchilli et al. 1996),

TABLE 1. Main specifications of the KICT radar.

\begin{tabular}{ll}
\hline \multicolumn{1}{c}{ Parameter } & \multicolumn{1}{c}{ Value } \\
\hline Frequency & $9410 \pm 30 \mathrm{MHz}$ \\
Peak power output & $8.0 \mathrm{~kW}$ (per channel) \\
Maximum duty cycle & $0.16 \%$ \\
Maximum coverage range & $40 \mathrm{~km}$ \\
Gain & $41 \mathrm{~dB}$ \\
Polarization & Dual linear, horizontal \\
& and vertical channels \\
Antenna type (diameter) & Front-fed parabolic $(1.8 \mathrm{~m})$ \\
Scan speed & Up to $60^{\circ} \mathrm{s}^{-1}$ \\
Sampling resolution & $1.2-192 \mathrm{~m}$ \\
Pulse repetition & $2.0 \mathrm{kHz}$ (maximum) \\
3-dB beamwidth & $1.4^{\circ}$ \\
\hline
\end{tabular}

TABLE 2. Configurations and physical parameters of the WRF Model.

\begin{tabular}{lcc}
\hline \hline \multicolumn{1}{c}{ Configuration } & Outer domain & Inner domain \\
\hline WRF version & $382 \times 373 \quad$ V3.5.1 & $400 \times 382$ \\
Horizontal grids & 5000 & 1000 \\
Grid spacing (m) & 50 layers (top at 50 hPa) \\
Vertical grid & 30 & 6 \\
Integration time (s) & Unified Model regional model \\
Initial boundary condition & forecast field (12-km \\
& resolution, KMA) \\
Radiation & RRTM longwave and Dudhia \\
& shortwave radiation \\
Microphysics & \multicolumn{1}{c}{ WDM 6-class } \\
Surface layer & Monin-Obukhov (Janjić) \\
& scheme \\
Land surface & Unified Noah LSM \\
Planetary boundary layer & Mellor-Yamada-Janjić TKE \\
& scheme, integration time: \\
Cumulus & 5 min per step \\
Land-use and topography data & CPS \\
\hline
\end{tabular}

and $K_{\mathrm{dp}}$ estimation (Wang and Chandrasekar 2009) conducted using the algorithms described by Chen et al. (2017).

The MERRA data (obtained at 0300 and 0600 UTC 12 December 2013) were utilized to describe the atmospheric parameters of the studied event. It was generated by the Global Modeling and Assimilation Office (GMAO) of the National Aeronautics and Space Administration (NASA) for the Goyang region using the Goddard Earth Observing System, version 5 (GEOS-5), data assimilation system (Rienecker et al. 2011). The vertical velocity $(W)$, cloud ice mixing ratio (QI), cloud liquid water mixing ratio $(\mathrm{QL})$, environmental relative humidity $(\mathrm{RH})$, and temperature $(T)$ parameters were extracted to describe the growth of precipitation particles.

WRF is a state-of-the-art numerical weather prediction model widely used for operational forecasting and meteorological research (Skamarock et al. 2008). In this study, the WRF Model, version 3.5.1, was utilized to describe the microphysics of the snow growth processes. The nonhydrostatic incompressible model was developed by the National Center for Atmospheric Research (NCAR) in the United States. It used a one-way nested domain and was configured in the Lambert conformal map projection with the central latitude of $38^{\circ} \mathrm{N}$ and longitude of $126^{\circ} \mathrm{E}$. The resolutions were $5 \mathrm{~km}$ with a $382 \times 373$ grid and $1 \mathrm{~km}$ with a $400 \times 382$ grid for the outer and inner domains, respectively. The inner domain covered Seoul metropolitan city and its surrounding areas. The outer 
(a)

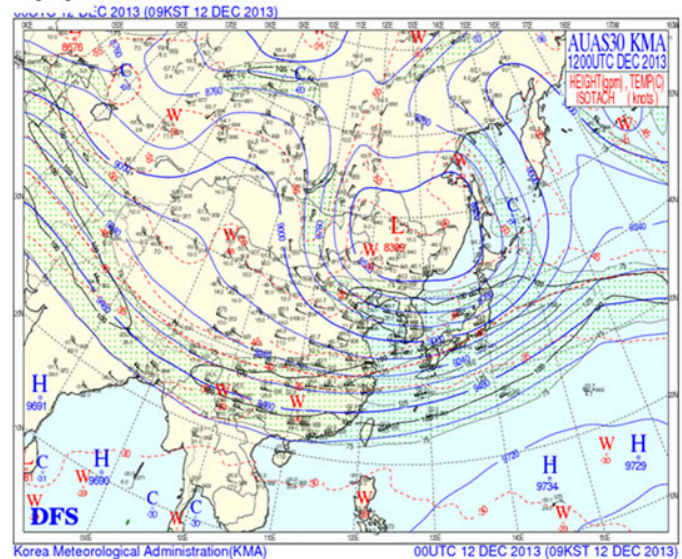

(c)

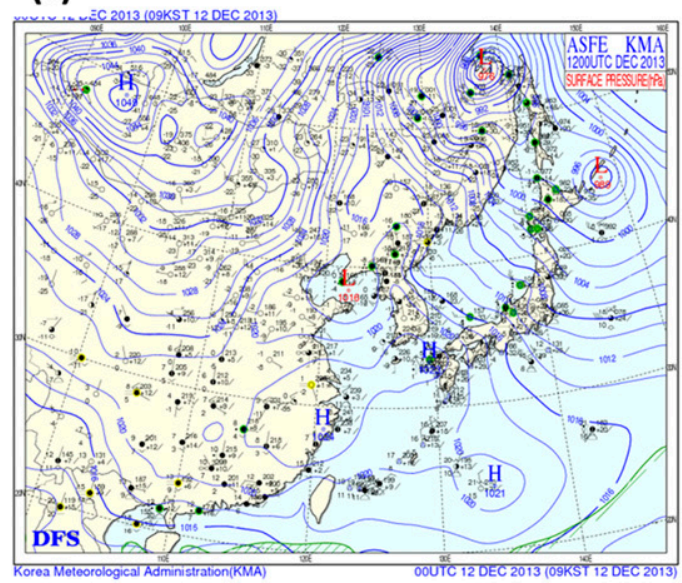

(b)

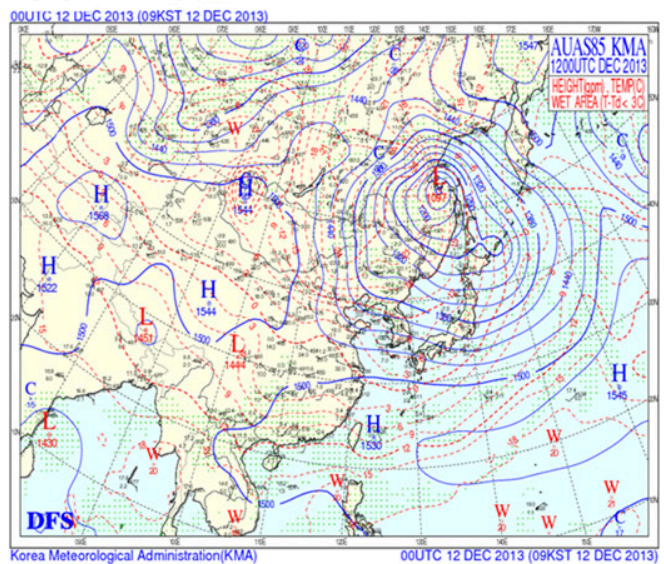

(d)

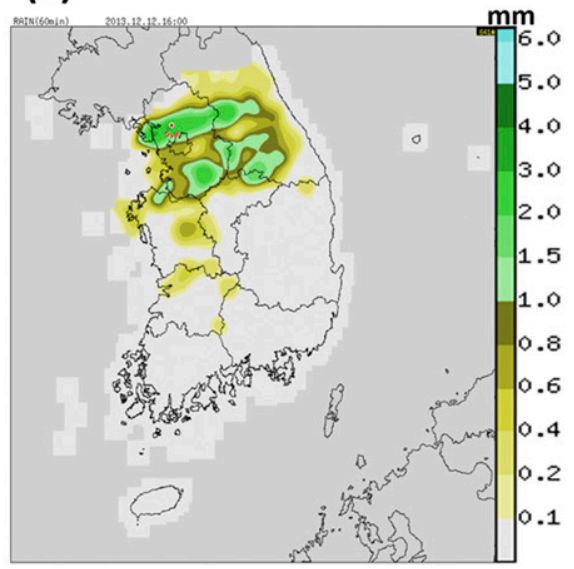

(e)

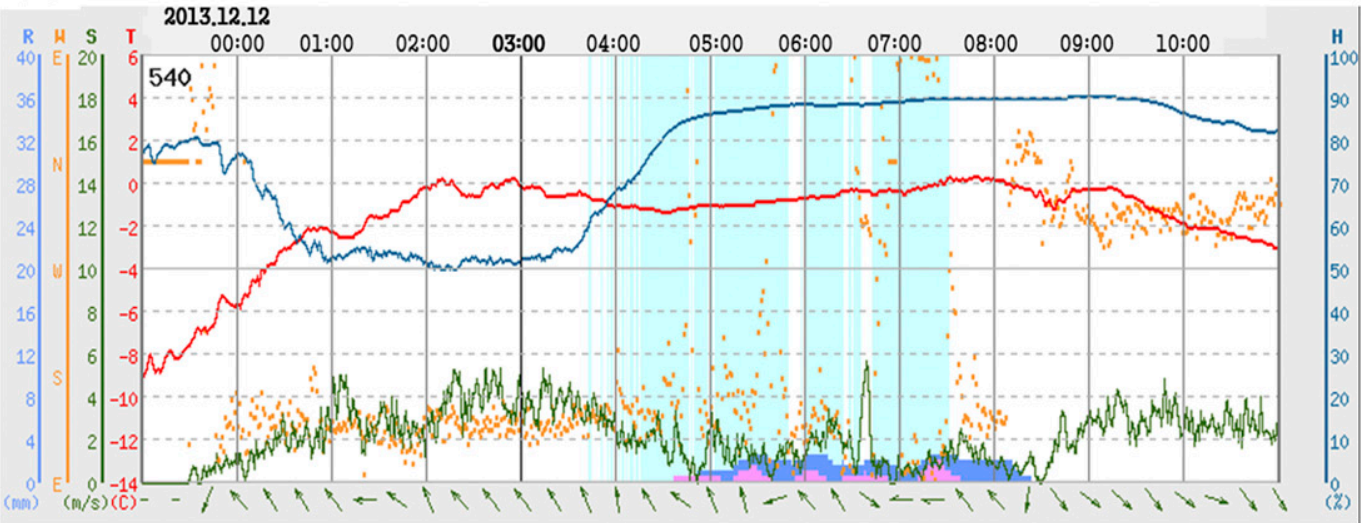

FIG. 4. Synoptic weather maps obtained at (a) $300 \mathrm{hPa}$, (b) $850 \mathrm{hPa}$, and (c) the surface at $0000 \mathrm{UTC} 12 \mathrm{Dec} 2013$. (d) AWS hourly precipitation observed at 0700 UTC 12 Dec 2013. (e) Time series of the AWS observational data obtained for the Goyang City $\left(37.6343^{\circ} \mathrm{N}, 126.8917^{\circ} \mathrm{E}\right)$. Denoted are the temperature (red line), humidity (blue line), wind direction (orange dots), wind speed (green line), precipitation (blue and pink shading), and time of occurrence (sky blue shading). The top axis shows the time (UTC). 

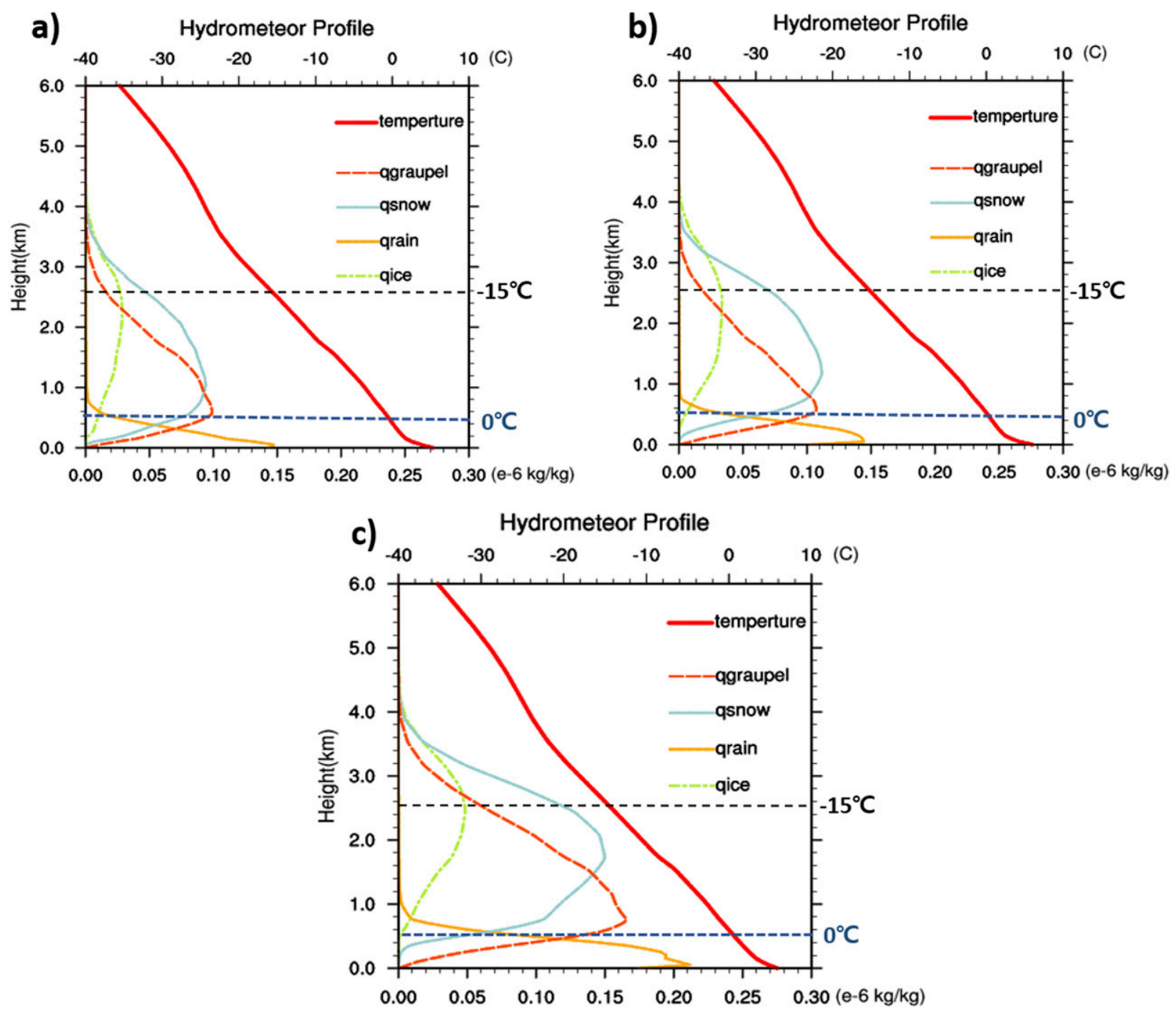

FIG. 5. Vertical hydrometeor and temperature profiles obtained for Seoul from the WRF Model data at (a) 0400, (b) 0500, and (c) 0700 UTC.

domain passed down large-scale information to the inner domain and prevented the appearance of instabilities around the lateral boundary by creating a buffer zone for the artifacts entering into the inner domain. The physical parameterization procedure included the Yonsei University planetary boundary layer scheme, WRF double-moment 6-class microphysics scheme (WDM6), unified Noah land surface model (LSM), and Rapid Radiative Transfer Model (RRTM) longwave and Dudhia shortwave radiation schemes (WDM6 utilized two-moment schemes for rain and cloud and single-moment schemes for ice and snow). These schemes were found to be applicable to the East Asia region (Min et al. 2015), and their configurations and physical parameters are listed in Table 2.

\section{b. Synoptic overview}

Three hours before the snowstorm (at 0000 UTC 12 December 2013), a cutoff low was formed over northern China, and a circular jet stream with a velocity of $60 \mathrm{~m} \mathrm{~s}^{-1}$ was observed at $300 \mathrm{hPa}$ (Fig. 4a). At 700$850 \mathrm{hPa}$, a broad upper-level trough has been identified west of the Korean Peninsula, which extended from the low pressure system located near the Sea of Okhotsk (Fig. 4b). This resulted in the formation of a surface cyclone over the Bay of Bohai, which brought relatively warm and humid air into the Seoul metropolitan area before the snowstorm (Fig. 4c). Later, a surface cold front was formed over the Yellow Sea, and the cold air moved toward the Seoul region. These two air masses (the warm air from the northwest and cold air from the 
southwest) converged over the Seoul area leading to the development of a squall line (see the temperature profile depicted in Fig. 4e, which shows that the temperature was below $0^{\circ} \mathrm{C}$ at this particular time). The squall line was composed of an updraft ascending from the ground level to higher altitudes, which resulted in the condensation of water vapor and creation of a heavy snowfall. High rates of precipitation (up to $5.8 \mathrm{~mm} \mathrm{~h}^{-1}$ ) were also observed on the ground (Fig. 4d). Figure 4e shows the temperature and humidity time series data obtained by the automatic weather station (AWS) located in Goyang City at a distance of about $13 \mathrm{~km}$ southeast of the KICT radar $\left(37.6343^{\circ} \mathrm{N}, 126.8917^{\circ} \mathrm{E}\right.$; see Fig. 3), which was maintained by the Korea Meteorological Administration (KMA). Figure $4 \mathrm{e}$ shows that the humidity level was low $(<60 \%)$ until 0300 UTC and suddenly increased at 0330 UTC, which signified the convergence of the cold and warm humid airstreams. The humidity remained high until 0900 UTC conducive to the rapid growth of snow particles and decreased afterward.

\section{X-band polarimetric radar observations of the winter snowstorm}

This section describes the distinct polarimetric radar signatures of the studied storm from its development to the maturity and dissipation stages. The storm started at 0200 UTC, intensified between 0600 and 0800 UTC, and weakened afterward.

\section{a. Dendritic growth of ice crystals and early aggregation}

The vertical hydrometeor, snow growth, and temperature profiles obtained from the WRF Model data over Seoul are shown in Fig. 5. Figures 5a-c contain the profiles recorded at 0400, 0500, and 0700 UTC, respectively, indicating that the temperature at a height of $2.6 \mathrm{~km}$ was about $-15^{\circ} \mathrm{C}$. Figure 6 a depicts the RHI scans of the $Z_{\mathrm{h}}, Z_{\mathrm{dr}}, K_{\mathrm{dp}}, \rho_{\mathrm{hv}}$, and SW parameters conducted at 0334 UTC. The distinctly high $Z_{\mathrm{dr}}$ and $K_{\mathrm{dp}}$ values were observed at an altitude of $2.6 \mathrm{~km}$ corresponding to a temperature of $-15^{\circ} \mathrm{C}$; these were associated with the $\rho_{\mathrm{hv}}$ depression and a strong vertical gradient of $Z_{\mathrm{h}}$, which suggested the growth of dendrites or platelike ice particles with low axis ratios and relatively high densities. This signature has been widely reported in the literature (see section 1 ). The R-QVP vertical extents of $Z_{\mathrm{h}}, Z_{\mathrm{dr}}, K_{\mathrm{dp}}, \rho_{\mathrm{hv}}$, and SW extracted from the $9-19-\mathrm{km}$ range of the RHI scan (depicted in the red rectangular boxes in Fig. 6a) are illustrated in Fig. 6b (top row). The obtained
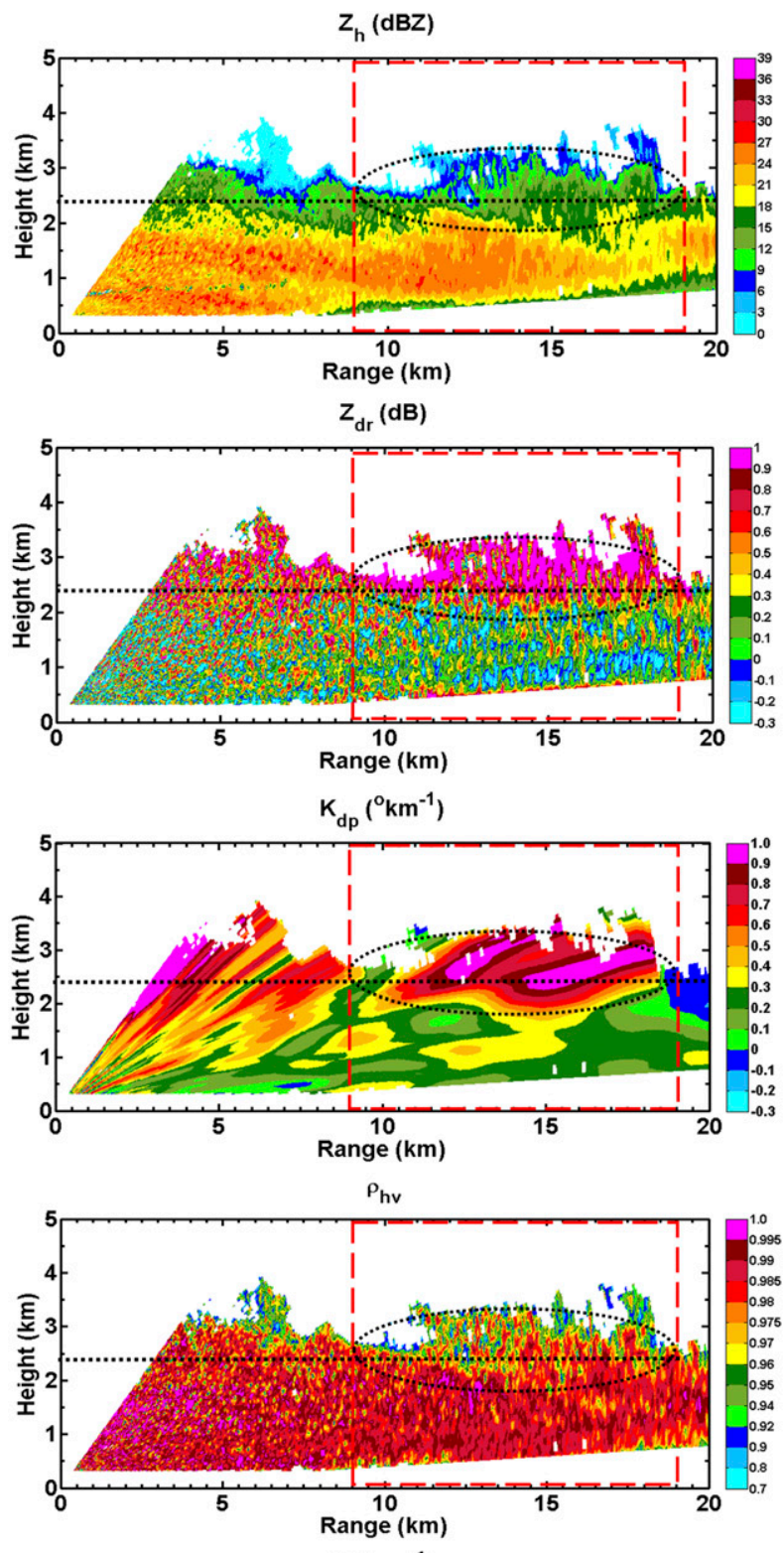

$\mathrm{SW}\left(\mathrm{ms}^{-1}\right)$

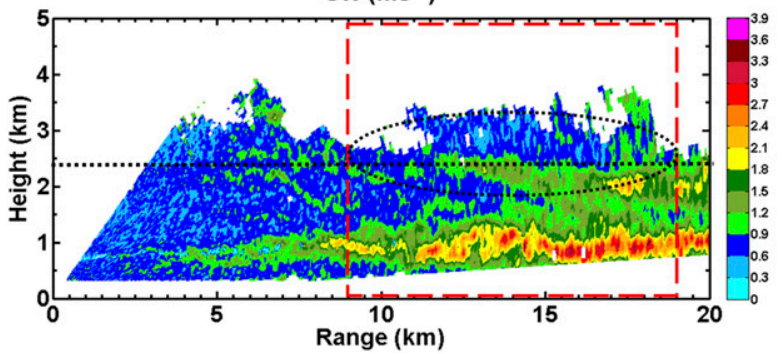

FIG. 6a. RHI scan obtained along the $306^{\circ}$ azimuth for (top to bottom) $Z_{\mathrm{h}}, Z_{\mathrm{dr}}, K_{\mathrm{dp}}, \rho_{\mathrm{hv}}$, and SW at 0334 UTC to elucidate the dendritic growth mechanism. The dashed ellipses represent the dendritic growth zone. The horizontal line indicates the $-15^{\circ} \mathrm{C}$ isotherm. The data in the rectangular boxes are used to obtain the averaged vertical profiles. 

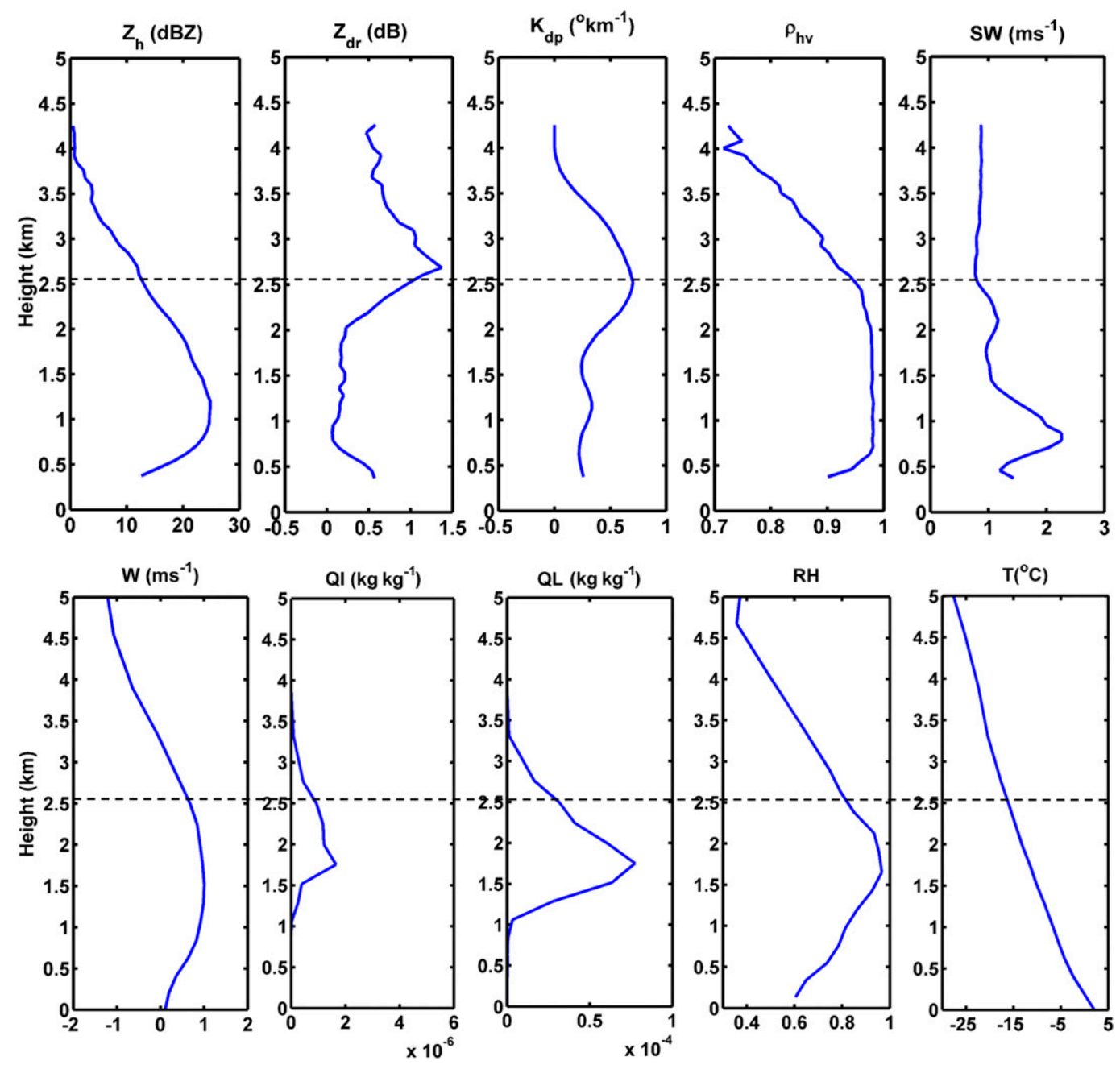

FIG. 6b. (top) R-QVP vertical profiles of (left to right) $Z_{\mathrm{h}}, Z_{\mathrm{dr}}, K_{\mathrm{dp}}, \rho_{\mathrm{hv}}$, and SW extracted from the 9-19-km range [red rectangular boxes in (a)] of the RHI scan obtained at 0334 UTC. (bottom) Profiles of (left to right) $W$, QI, QL, RH, and $T$ obtained from the MERRA dataset at 0300 UTC. The horizontal dashed lines indicate the $-15^{\circ} \mathrm{C}$ isotherm.

vertical profiles contain the distinct maxima of the $Z_{\mathrm{dr}}$ $(\sim 1.2 \mathrm{~dB})$ and $K_{\mathrm{dp}}\left(\sim 0.86^{\circ} \mathrm{km}^{-1}\right)$ bands. Thus, it can be hypothesized that ice particles fell into the moist layer with a temperature of around $-15^{\circ} \mathrm{C}$ (corresponding to a height between 2 and $3.2 \mathrm{~km}$ ) and started transforming into dendrite-like crystals that exhibited these dual-polarization signatures with enhanced $Z_{\mathrm{dr}}$ and $K_{\text {dp }}$ values.

As the crystals fall toward the ground, the particle growth mechanism changes from the dendritic to aggregation (Houze 2014; Magono and Lee 1966). Figure 6b (bottom row) shows the vertical profiles of $W$, QI, QL, $\mathrm{RH}$, and $T$ obtained from the MERRA dataset. The high $W$ and SW values observed at a height below $2.6 \mathrm{~km}$ indicate the existence of turbulence/updraft on the ground. The high liquid water content (LWC) (represented by
QL) associated with the high RH is also detected in this height range $\left(T>-15^{\circ} \mathrm{C}\right)$. The high updrafts (with large $\mathrm{RH})$ can increase the LWC and amount of cloud ice (QI) aloft and initiate the growth of ice particles (Chu et al. 2018). As a result, the number of ice particle collisions increases in the turbulent layer at a height below $2.6 \mathrm{~km}$, thus increasing the fall speed of precipitation particles and $W$ magnitude. Additionally, the values of $Z_{\mathrm{h}}$ and $\mathrm{W}$ start to increase exactly at the height of the enhanced $K_{\mathrm{dp}}$ band, suggesting the transition of the hydrometeor. Further, $Z_{\mathrm{dr}}$ and $K_{\mathrm{dp}}$ maxima do not occur at the same height with the $Z_{\mathrm{dr}}$ maximum slightly above the maximum of $K_{\mathrm{dp}}$. There may also be new ice crystals grown in this layer (Moisseev et al. 2015). At warmer temperatures $\left(>-15^{\circ} \mathrm{C}\right)$, dendrite-like crystals with multiple branches exhibit high sticking probabilities and, therefore, will form 
early aggregates upon collision (Houze 2014; Magono and Lee 1966; Pruppacher and Klett 1997; Wallace and Hobbs 2006).

\section{b. Heavy snowfall and dense aggregation}

After obtaining the radar signatures with high $Z_{\mathrm{dr}}$ $(\sim 1.2 \mathrm{~dB})$ and positive $K_{\mathrm{dp}}\left(\sim 0.86^{\circ} \mathrm{km}^{-1}\right)$ values at around 0330 UTC, a heavy snowfall occurred on the ground, as indicated by the results of the AWS measurements ( $\sim 0430$ UTC shown in Fig. 4$)$ and ground observations. The blue and pink shaded areas in Fig. $4 \mathrm{e}$ represent the high surface precipitation zones detected by the AWS. Furthermore, a moderate snowfall has been observed (Fig. 8) with a peak precipitation rate of $5.8 \mathrm{~mm} \mathrm{~h}^{-1}$ (Fig. 4d). Thus, it can be suggested that the enhanced (positive) $K_{\mathrm{dp}}$ band aloft is a precursor to heavy surface precipitation (Bechini et al. 2013; Kennedy and Rutledge 2011; Kumjian and Lombardo 2017; Moisseev et al. 2015; Schrom et al. 2015). The RHI scan taken at 0519 UTC (Fig. 7a) indicates that dense aggregation and heavy snowfall occurred on the ground. The high $Z_{\mathrm{dr}}$ and low $Z_{\mathrm{h}}$ values were found at a height above $2.5 \mathrm{~km}(\mathrm{~T}<$ $-15^{\circ} \mathrm{C}$ ) within the $5-20-\mathrm{km}$ range. Below this level, these variables exhibited the opposite trend. The negative correlation between the $Z_{\mathrm{h}}$ and $Z_{\mathrm{dr}}$ parameters indicates the aggregation of ice particles since the formed aggregates become bigger and less anisotropic. The R-QVP vertical profiles of $Z_{\mathrm{h}}, Z_{\mathrm{dr}}, K_{\mathrm{dp}}$, $\rho_{\text {hv }}$, and SW (Fig. 7b) were extracted from the 8 $18-\mathrm{km}$ range of the RHI scan (depicted in the red rectangular boxes in Fig. 7a). The MERRA data were not available for this particular time. The measured values of $Z_{\mathrm{h}}$ (around $25 \mathrm{dBZ}$ ), $\rho_{\mathrm{hv}}(>0.98)$, and $\mathrm{SW}$ were higher than those obtained for dendritic particles, while the magnitudes of $Z_{\mathrm{dr}}$ (around $0.2 \mathrm{~dB}$ ) and $K_{\mathrm{dp}}$ (around $0^{\circ} \mathrm{km}^{-1}$ ) were relatively low, indicating the presence of low-density large aggregates (at a height below $2.5 \mathrm{~km}$ ). The corresponding in situ photographs obtained at 0518 UTC (Fig. 8) show the reduction of visibility range due to the snowfall and formation of large aggregates.

\section{c. Riming and graupel formation}

The riming process occurs through the collision of ice particles with supercooled liquid water (SLW) drops below the freezing point as the drops impinge on the ice surface. The obtained RHI scan (Fig. 9a) shows that the high $Z_{\mathrm{h}}(30-40 \mathrm{~dB} Z)$ and $\rho_{\mathrm{hv}}(>0.98)$ values collocated with the low $Z_{\mathrm{dr}}(\leq 0 \mathrm{~dB})$ and $K_{\mathrm{dp}}$ $\left(\leq 0^{\circ} \mathrm{km}^{-1}\right)$ magnitudes in the range between 5 and $15 \mathrm{~km}$ (at a height below $2.5 \mathrm{~km}$ ), which may signify the riming process. Further, the high values of SW
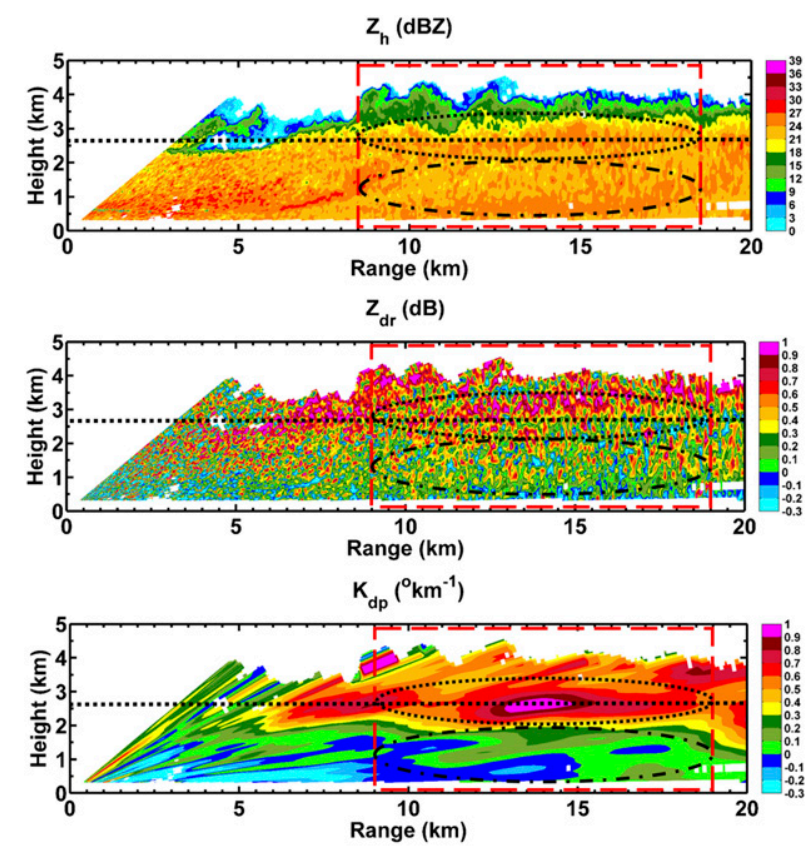

$\rho_{\mathrm{hv}}$
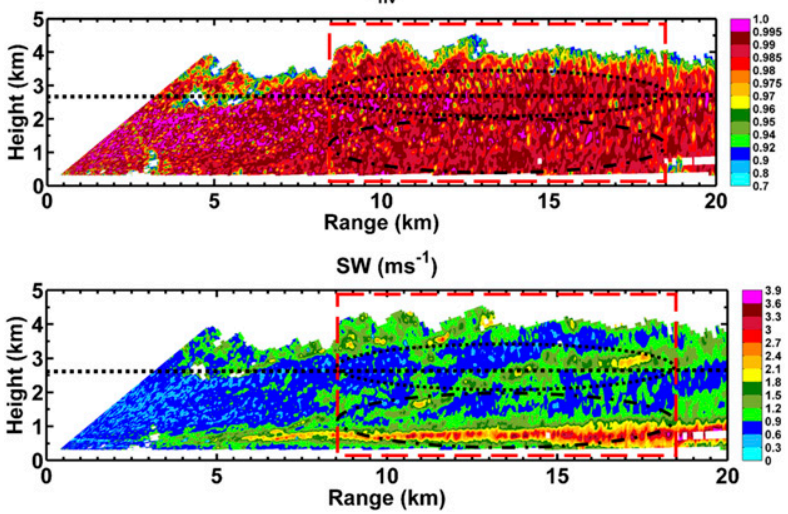

FIG. 7a. RHI scan obtained along the $108^{\circ}$ azimuth for (top to bottom) $Z_{\mathrm{h}}, Z_{\mathrm{dr}}, K_{\mathrm{dp}}, \rho_{\mathrm{hv}}$, and SW at 0519 UTC to elucidate the aggregation mechanism. The dashed ellipses represent the dendritic growth zone associated with aggregate embryos, and the dash-dotted ellipses denote the aggregation zone of ice crystals. The horizontal lines indicate the $-15^{\circ} \mathrm{C}$ isotherm. The data in the rectangular boxes are used to obtain the averaged vertical profiles.

observed in this range are consistent with intense riming. It should be also noted that the $Z_{\mathrm{h}}$ values measured during the intense riming process are higher than those obtained in the periods of dendritic growth and aggregation. On the other hand, the magnitudes of $Z_{\mathrm{dr}}$ and $K_{\mathrm{dp}}$ are smaller than the values determined for the dendritic and aggregation processes. The riming process makes crystals more isotropic as indicated by the low $Z_{\mathrm{dr}}$ and high $\rho_{\mathrm{hv}}$ values. Figure $9 \mathrm{~b}$ (top row) shows the R-QVP profiles of $Z_{\mathrm{h}}, Z_{\mathrm{dr}}, K_{\mathrm{dp}}, \rho_{\mathrm{hv}}$, and SW extracted from the $5-15-\mathrm{km}$ range of the RHI 


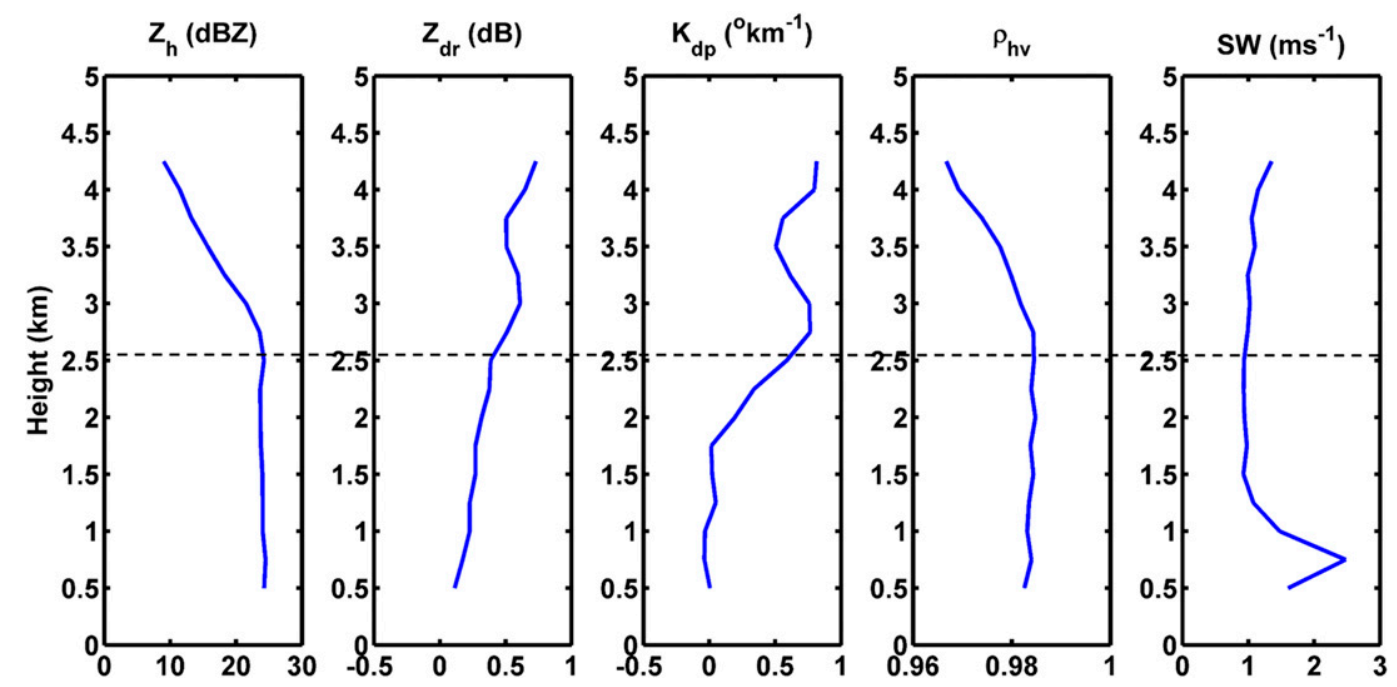

FIG. 7b. R-QVP vertical profiles of (left to right) $Z_{\mathrm{h}}, Z_{\mathrm{dr}}, K_{\mathrm{dp}}, \rho_{\mathrm{hv}}$, and SW extracted from the 8-18-km range [red rectangular boxes in (a)] of the RHI scan obtained at 0519 UTC. The horizontal dashed line indicates the $-15^{\circ} \mathrm{C}$ isotherm.

scan (depicted in the red rectangular boxes in Fig. 9a). The vertical extents of $W$, QI, QL, RH, and $T$ obtained from the MERRA data are also presented in Fig. 9b (bottom row). The observed high $W\left(>1 \mathrm{~m} \mathrm{~s}^{-1}\right)$, SW $\left(>2 \mathrm{~m} \mathrm{~s}^{-1}\right)$, and $Z_{\mathrm{h}}$ values suggest the relatively strong shear and turbulence on the ground that was likely caused by convection. In addition, Fig. 4 suggests that the convergence of the two air masses (the cold and warm streams) may be responsible for the measured $W$ values. The updrafts associated with the convective instability are observed in the bottom part of the mixed-phase clouds, where liquid water coexists with ice (Michimoto 1991). Further, the large amounts of cloud ice and LWC collocated with the high $\mathrm{RH}$ at heights between 1.5 and $4 \mathrm{~km}$ (Fig. 9b), supporting the optimal riming conditions. Under these conditions, a larger number of SLW droplets likely freeze on the surface of ice particles. The riming process increases the density of precipitating particles, thereby raising their fall speed (as indicated by the observed increase in $W$ ). As a result, the rimed particles rapidly fall to the ground. The riming process consumed the entire liquid water $(\mathrm{QL})$; therefore, the $\mathrm{LWC}$ is low or equals zero at lower heights.

Intense riming processes may produce graupel as was observed near the end of the storm. Figure 10 shows the PPI scan taken at 0647 UTC. Distinct SW and velocity features were observed at a distance between 20 and $28 \mathrm{~km}$ west (between -10 and $0 \mathrm{~km}$ south) from the radar. The region corresponding to $\mathrm{SW}>2.5 \mathrm{~m} \mathrm{~s}^{-1}, W>$ $12 \mathrm{~m} \mathrm{~s}^{-1}$, and $Z_{\mathrm{h}}>25 \mathrm{~dB} Z$ suggests that the convective turbulence associated with SLW droplets is ideal for graupel formation. Various shapes of graupel particles produce different polarimetric radar signatures, as has been reported in the literature (see section 1 ). The high $Z_{\mathrm{h}}(>30 \mathrm{~dB} Z)$ and low $Z_{\mathrm{dr}}$ (from -0.2 to $-0.5 \mathrm{~dB}$ ) values combined with $\rho_{\mathrm{hv}} \sim 0.99$ indicate the formation of prolate or conical graupel at a distance of around $18 \mathrm{~km}$ west $(-12 \mathrm{~km}$ south) from the radar. Additionally, the high $Z_{\mathrm{h}}(>30 \mathrm{~dB} Z)$ and low but positive $Z_{\mathrm{dr}}$ $(>0.5 \mathrm{~dB})$ values measured at a $24-\mathrm{km}$ distance west ( $-6 \mathrm{~km}$ south) from the radar suggest the formation of lump or hexagonal graupel, which can be indeed confirmed by ground observations. Figure 11a shows the rimed snow/graupel falling to the surface, whose shape is depicted in Fig. 11b. The corresponding RHI scan taken along the $125^{\circ}$ azimuth is shown in Fig. 12. In the range between 15 and $18 \mathrm{~km}$ (with high $Z_{\mathrm{h}}$, negative $Z_{\mathrm{dr}}$, and negative $K_{\mathrm{dp}}$ values), conical graupel might be formed; while lump or hexagonal graupel were noticed at a distance of $18-20 \mathrm{~km}$ (with high $Z_{\mathrm{h}}$, near zero or negative $Z_{\mathrm{dr}}$, and positive $K_{\mathrm{dp}}$ values). Figure 5c (the WRF Model output) shows that the graupel features are predominant at $0700 \mathrm{UTC}$ in the height range of $0.5-2.5 \mathrm{~km}$. The polarimetric signatures depicted in Fig. 12 also contain the graupel signatures obtained at 0644 UTC in the height range of $0.5-2.5 \mathrm{~km}$ as discussed above. Thus, the experimental data are in good agreement with the results of the WRF Model.

\section{Snowfall event interpretation: $R-Q V P$ vertical profiles}

Figure $4 \mathrm{e}$ shows that at $0330 \mathrm{UTC}$, when the cold front reached the Goyang region, the sudden increase in humidity and small decrease in temperature resulted in a heavy snowfall, which lasted until 


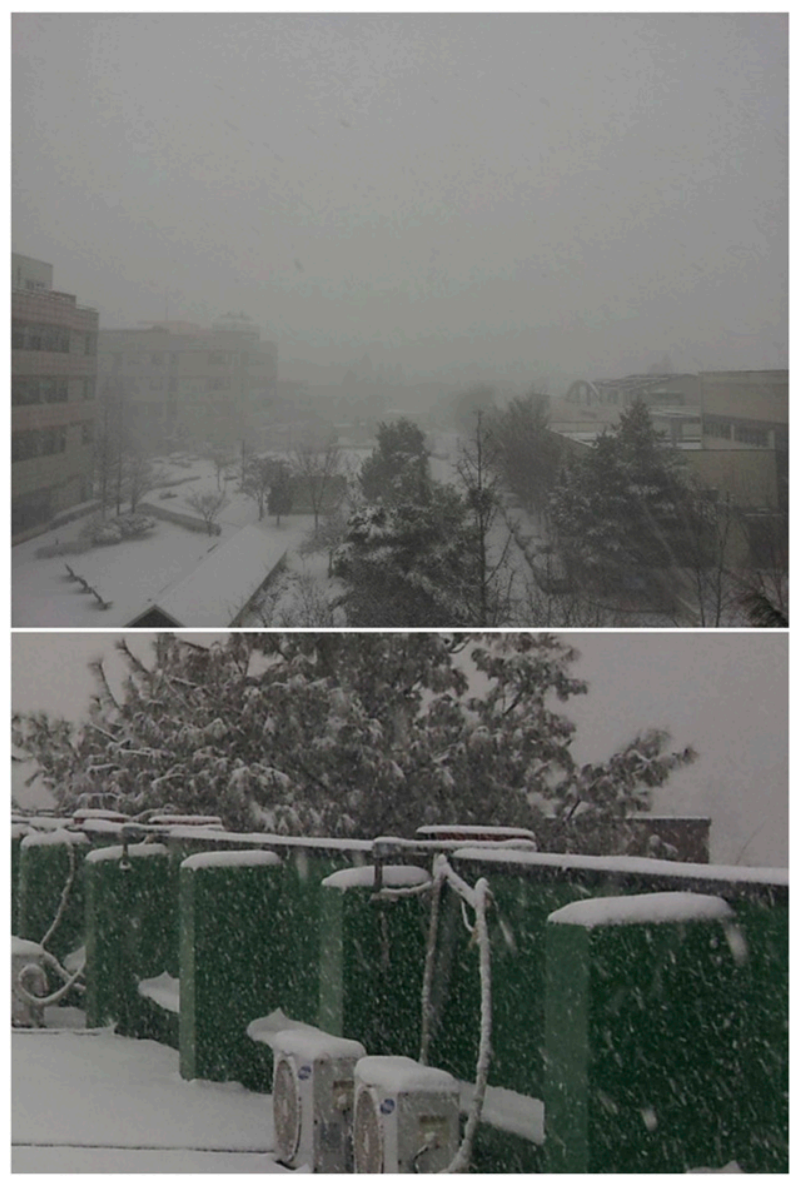

FIG. 8. Photographs illustrating the spatial visibility of the heavy snowfall and large aggregates on the surface at 0518 UTC.

0800 UTC and decreased afterward. Accordingly, the period between 0330 and 0730 UTC corresponds to the heavy snowfall event.

It is not possible to comprehensively describe the snow growth processes occurred throughout the entire event using only the RHI and PPI scans. Hence, the detailed illustration of the evolution of the ice growth processes for the total event was performed using the R-QVP methodology. The obtained R-QVP profiles clearly show the distinction of the snow habits and their growth through the spatial and temporal formats. The R-QVP profiles of $Z_{\mathrm{h}}, Z_{\mathrm{dr}}, K_{\mathrm{dp}}, \rho_{\mathrm{hv}}$, and SW related to the total snowfall event occurred in the Goyang region (at a $108^{\circ}$ azimuth) are shown in Fig. 13. The total event was divided into three categories based on the polarimetric radar signatures: (i) the growth of platelike or dendritic ice particles (from 0330 to 0430 UTC), (ii) aggregation (from 0430 to 0515 UTC), and (iii) heavy riming associated with the graupel formation (from 0515 to 0730 UTC). The first two events (occurred from 0330 to 0515 UTC) are

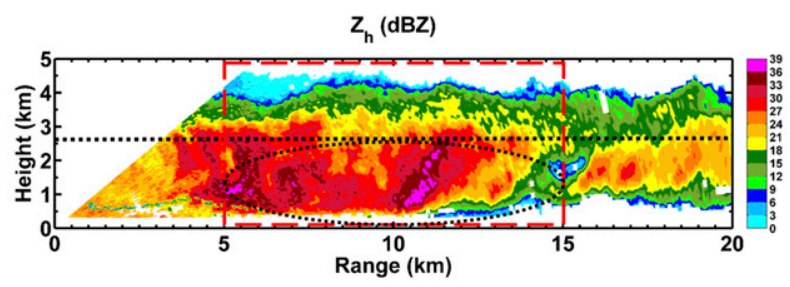

$\mathrm{Z}_{\mathrm{dr}}(\mathrm{dB})$

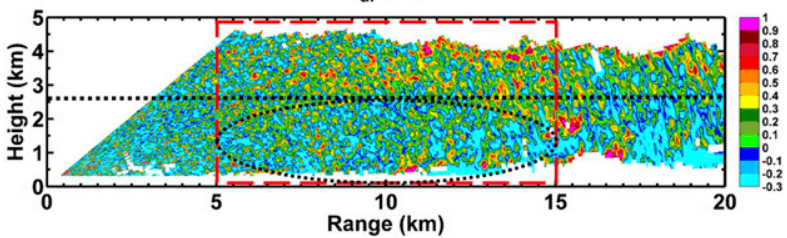

$\mathrm{K}_{\mathrm{dp}}\left({ }^{\mathrm{o}} \mathrm{km}^{-1}\right)$

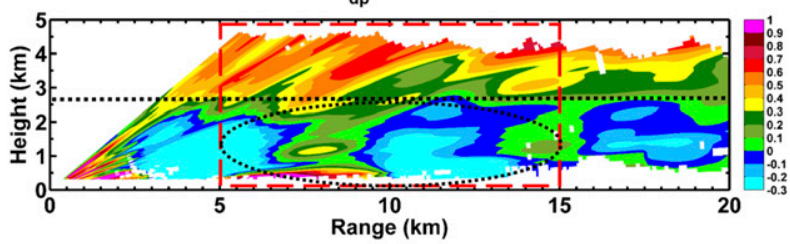

$\rho_{\mathrm{hv}}$

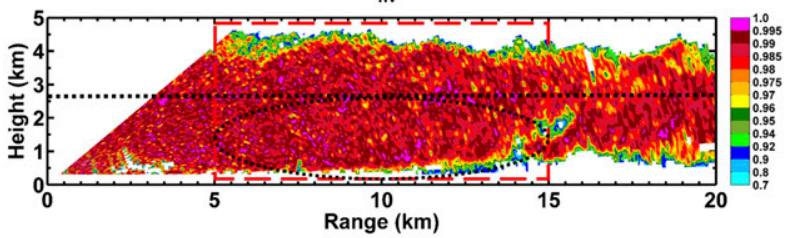

$\mathrm{SW}\left(\mathrm{ms}^{-1}\right)$

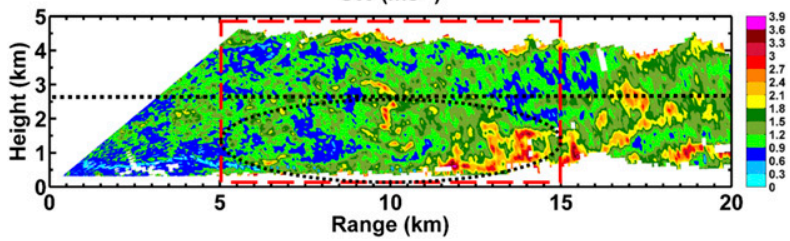

FIG. 9a. RHI scan obtained along the $306^{\circ}$ azimuth for (top to bottom) $Z_{\mathrm{h}}, Z_{\mathrm{dr}}, K_{\mathrm{dp}}, \rho_{\mathrm{hv}}$, and SW at $0559 \mathrm{UTC}$ to investigate the riming process. The dashed ellipses represent the riming zone of ice crystals. The horizontal lines indicate the $15^{\circ} \mathrm{C}$ isotherm. The data in the rectangular boxes are used to obtain the averaged vertical profiles.

classified into the upper-level (above $2 \mathrm{~km}$ ) and lowerlevel (below $2 \mathrm{~km}$ ) precipitation.

The upper-level precipitation (from 0330 to 0515 UTC) exhibits low $Z_{\mathrm{h}}(<15 \mathrm{~dB} Z)$, low $\rho_{\mathrm{hv}}(<0.985)$, high $Z_{\mathrm{dr}}$ $(>0.3 \mathrm{~dB})$, and high $K_{\mathrm{dp}}\left(>0.3^{\circ} \mathrm{km}^{-1}\right)$ values. The dendritic growth and onset of the aggregation process correspond to the strong $Z_{\mathrm{h}}$ gradient associated with the intense $Z_{\mathrm{dr}}$ and $K_{\mathrm{dp}}$ bands in the temperature range between $-10^{\circ}$ and $-20^{\circ} \mathrm{C}$ (Ryzhkov et al. 2016). It is worth noting that during the third event (occurred from 0515 to $0700 \mathrm{UTC})$, the $K_{\mathrm{dp}}\left(\geq 0.3^{\circ} \mathrm{km}^{-1}\right)$ and $Z_{\mathrm{dr}}(\leq 0.3 \mathrm{~dB})$ values were not as high as those observed in the period from 0330 to 0515 UTC, which 

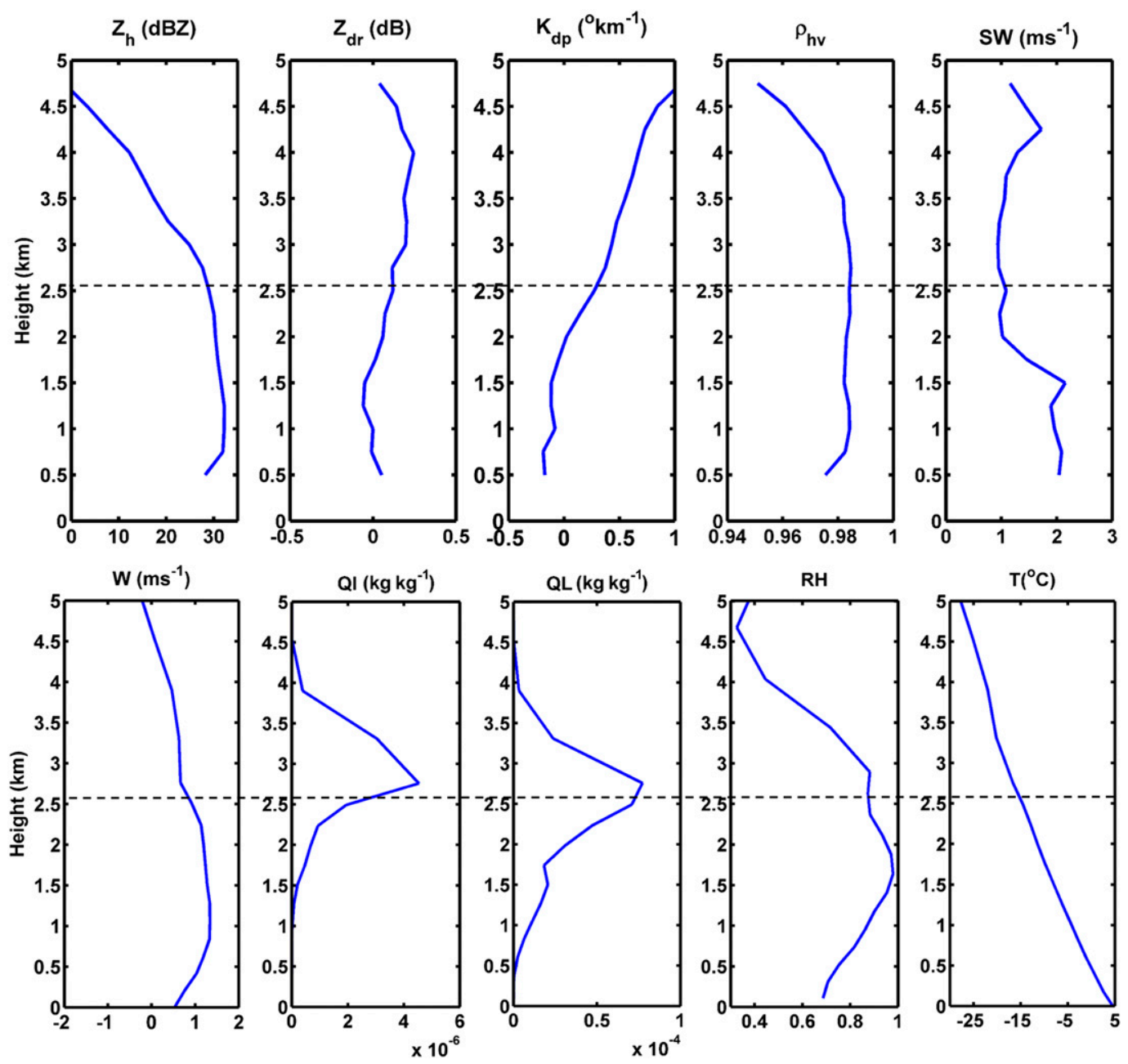

FIG. 9b. (top) R-QVP vertical profiles of (left to right) $Z_{\mathrm{h}}, Z_{\mathrm{dr}}, K_{\mathrm{dp}}, \rho_{\mathrm{hv}}$, and SW extracted from the 5-15-km range [red rectangular boxes in (a)] of the RHI scan at 0559 UTC. (bottom) Profiles of (left to right) $W$, QI, QL, RH, and $T$ obtained from the MERRA data at 0600 UTC. The horizontal dashed lines indicate the $-15^{\circ} \mathrm{C}$ isotherm.

correlated with the low $Z_{\mathrm{h}}$ and $\rho_{\mathrm{hv}}$ magnitudes. Thus, we advocate that the high $Z_{\mathrm{dr}}$ and $K_{\mathrm{dp}}$ values observed during the first two events (with shallow clouds from 0330 to 0515 UTC) signify that the dendrites (D-type ice crystals) are the dominant species; while the moderate $Z_{\mathrm{dr}}$ and high $K_{\mathrm{dp}}$ magnitudes obtained for the third event (with deep clouds from 0515 to 0700 UTC) indicate that the isometric (I-type) ice crystals with an aspect ratio of around 0.6 are predominant (Schrom and Kumjian 2016; Griffin et al. 2018).

The lower-level precipitation (below $2 \mathrm{~km}$ ) signifies the aggregation process. From 0330 through 0430 UTC (the first event), the $Z_{\mathrm{h}}$ values were below $\leq 21 \mathrm{~dB} Z$, the magnitudes of $Z_{\mathrm{dr}}$ and $K_{\mathrm{dp}}$ were slightly positive $\left(<0.3^{\circ} \mathrm{km}^{-1}\right)$, and $\rho_{\mathrm{hv}}>0.98$. These signatures indicate the reduction of particle anisotropy and initiation of the aggregation process (further, ice particles appear as early snow aggregates). During the second event (from 0430 to $0515 \mathrm{UTC})$, the observed $Z_{\mathrm{h}}(>20 \mathrm{~dB} Z$ ) values are greater than those measured at the previous stage (from 0330 to $0430 \mathrm{UTC}$ ). On the other hand, $Z_{\mathrm{dr}}$ is slightly negative (close to zero), $K_{\mathrm{dp}}$ remains the same, and $\rho_{\mathrm{hv}}>0.985$. The large $Z_{\mathrm{h}}$ and low $Z_{\mathrm{dr}}$ and $K_{\mathrm{dp}}$ values suggest intensified aggregation and the formation of small clusters as dense aggregates. During the third event (from 0515 to 0700 UTC), very interesting signatures were observed. The period between 0515 and 0610 UTC exhibited high $Z_{\mathrm{h}}$ (mostly $>24 \mathrm{~dB} Z$ ), negative $Z_{\mathrm{dr}}$, and slightly negative $K_{\mathrm{dp}}$ values with $\rho_{\mathrm{hv}} \geq 0.985$, indicating the formation of rimed ice crystals or rimed aggregates with small graupel due to heavy riming (Kouketsu et al. 2015). The spectrum width is also large during the process that riming becomes intense, which indicates intensified updraft and 

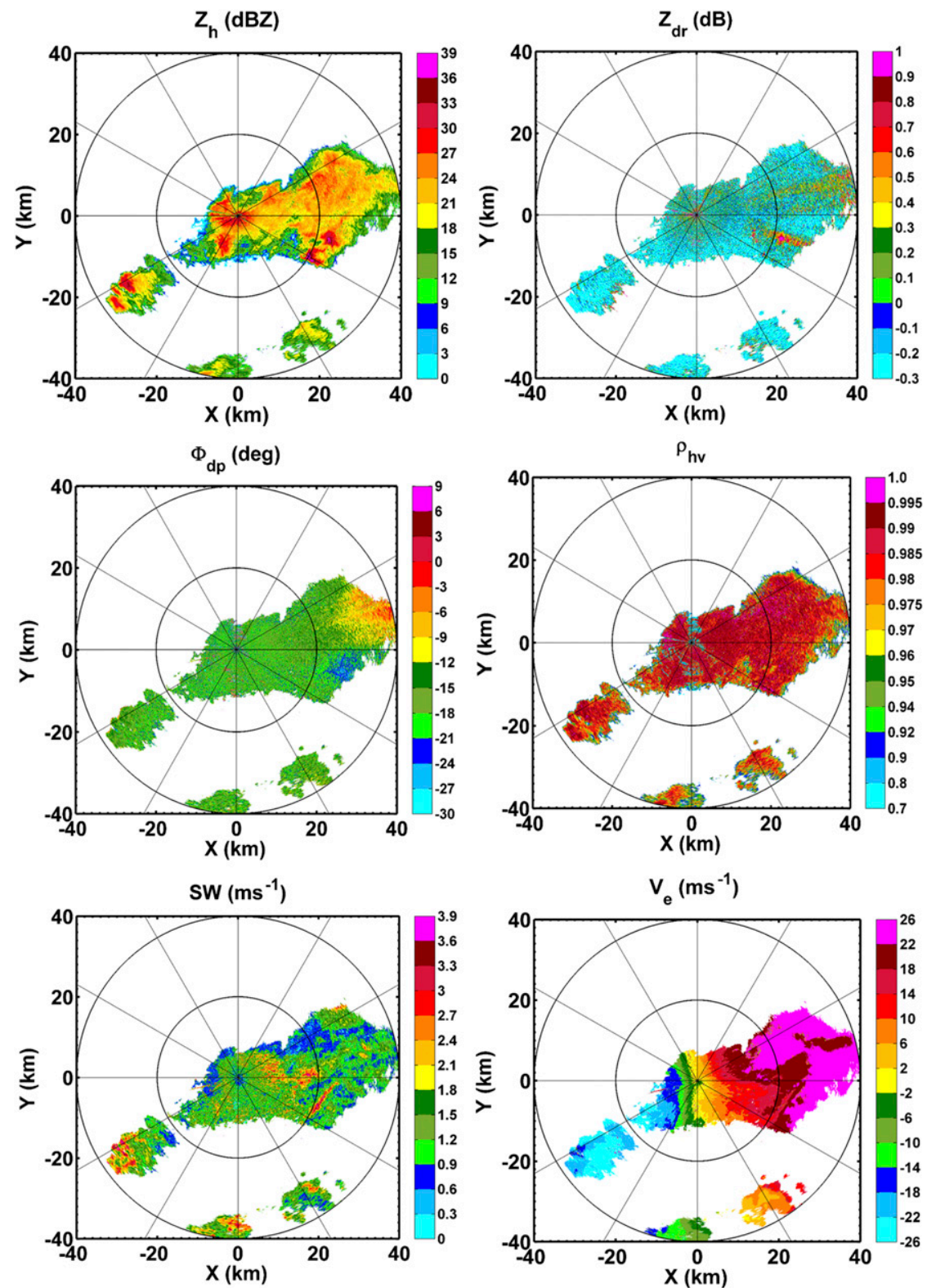

FIG. 10. Radar PPIs representing the graupel signatures obtained at 0647 UTC for (top left) $Z_{\mathrm{h}}$, (top right) $Z_{\mathrm{dr}}$, (middle left) $\Phi_{\mathrm{dp}}$, (middle right) $\rho_{\mathrm{hv}}$, (bottom left) $\mathrm{SW}$, and (bottom right) velocity.

pumps a large number of SLW droplets for riming. Further, riming aloft is consistent with high LWC (see QL) depicted in Fig. 9b (Ryzhkov et al. 2016). Toward the end of the event, the rimed particles transformed into large graupel particles. The pronounced negative $Z_{\mathrm{dr}}(<-0.1 \mathrm{~dB})$ and $K_{\mathrm{dp}}\left(<0^{\circ} \mathrm{km}^{-1}\right)$ values associated with high $Z_{\mathrm{h}}(>24 \mathrm{~dB} Z)$ and $\rho_{\mathrm{hv}}(>0.985)$ magnitudes were observed from 0610 to 0700 UTC. These signatures signify the conical and complex shapes of graupel particles (Aydin and Seliga 1984; Locatelli and Hobbs 1974). The shape of the graupel was also evident from the ground observations (see Fig. 11). Furthermore, the observed $W>1 \mathrm{~m} \mathrm{~s}^{-1}$ (Fig. 9b) may be indicative of the density and mass of the particles (Moisseev et al. 2015). Thus, we can state that the low $Z_{\mathrm{dr}}$ and near-zero $K_{\mathrm{dp}}$ values (0515-0610 UTC) are characteristics of rimed ice particles, while the high negative $Z_{\mathrm{dr}}$ and $K_{\mathrm{dp}}$ magnitudes (0610-0700 UTC) are typical for the large graupel particles with sizes of several millimeters. The evolution of the ice habits shown in Fig. 13 is in good agreement with the snow growth rates obtained via WRF Model simulations (Fig. 5 at 0400, 0500, and 


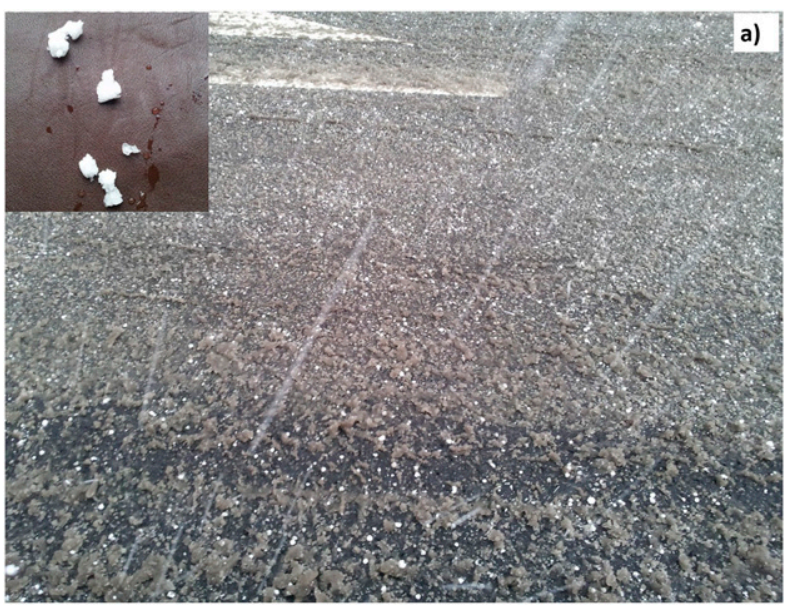

FIG. 11a. Spatial visibility of the graupel falling to the surface at 0647 UTC

0700 UTC). Table 3 lists various categories of microphysical species and the corresponding values of the polarimetric radar variables $\left(Z_{\mathrm{h}}, Z_{\mathrm{dr}}, K_{\mathrm{dp}}, \rho_{\mathrm{hv}}\right.$, and $\left.\mathrm{SW}\right)$ obtained from the visual representations for the studied event.

To classify the aggregation and riming processes, the variability factor $Z_{\mathrm{h}}$ was determined at lower and upper heights (here, the transition height at $2.5 \mathrm{~km}$ was taken as a reference) following the procedures developed by Moisseev et al. (2009) and Lim et al. (2013).

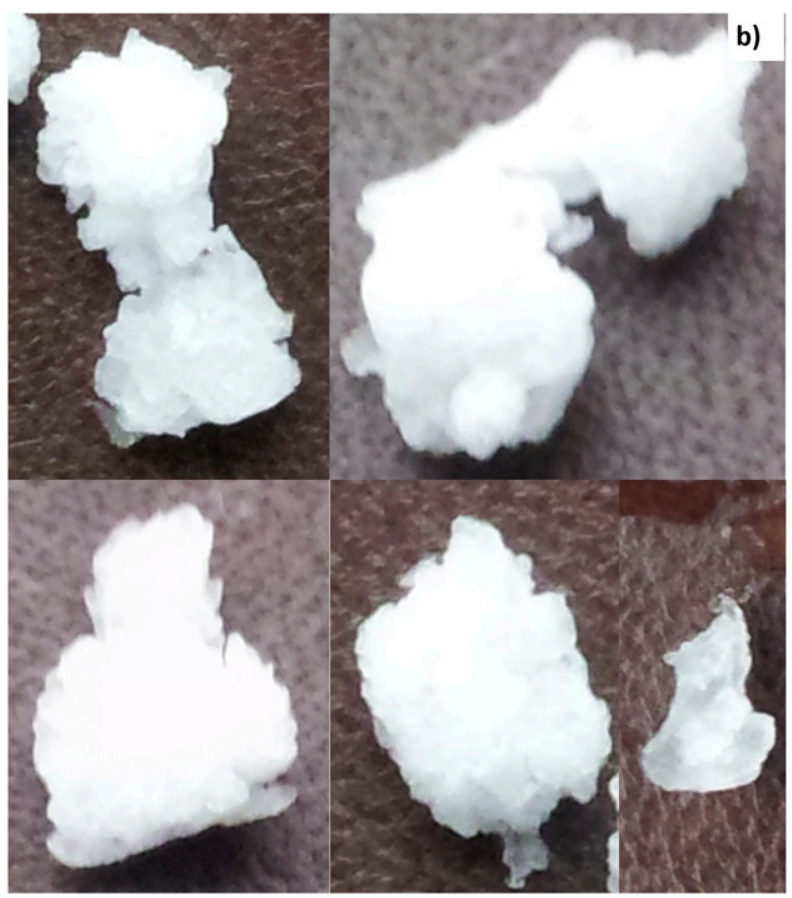

FIG. 11b. Different shapes of the graupel lying on the surface at 0647 UTC
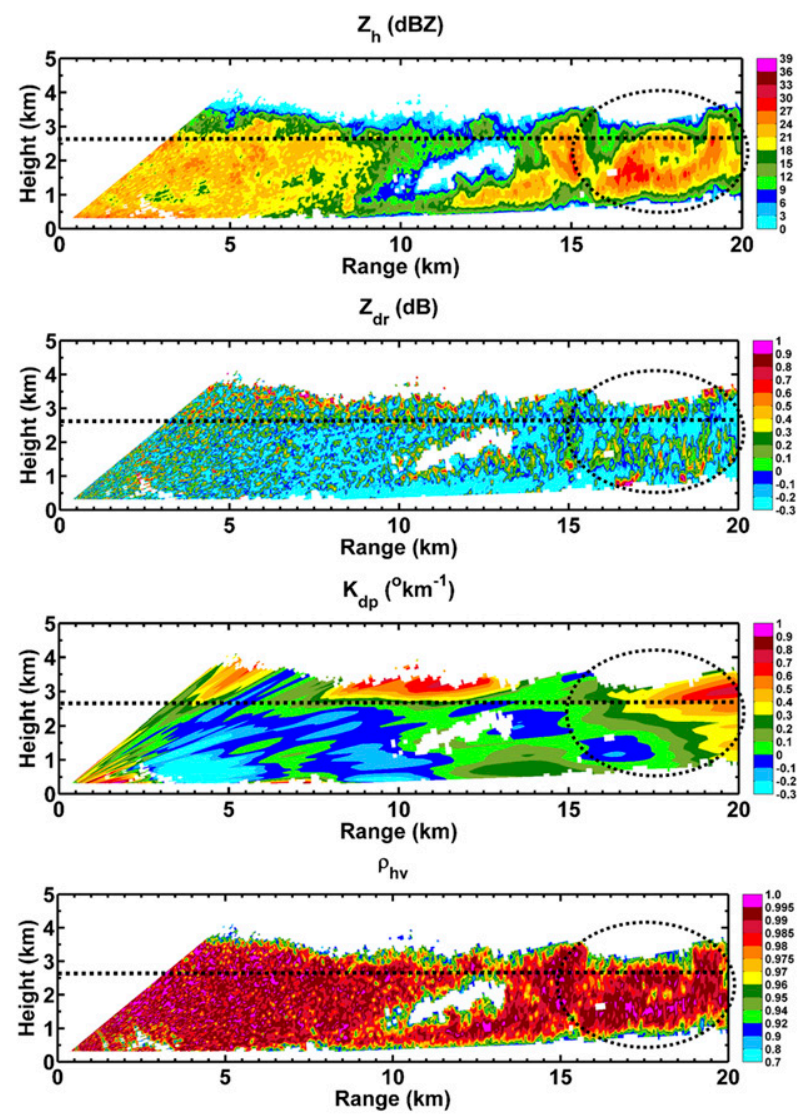

$\mathrm{SW}\left(\mathrm{ms}^{-1}\right)$

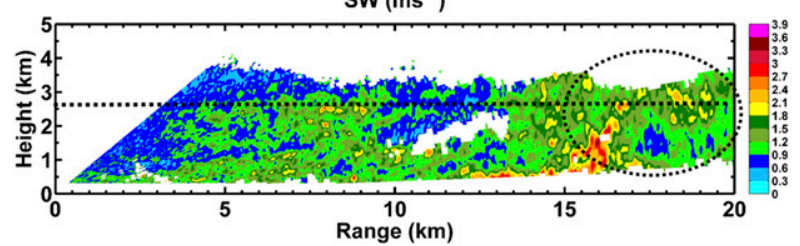

FIG. 12. Radar RHI scans representing the graupel signatures obtained along the $125^{\circ}$ azimuth for (top to bottom) $Z_{\mathrm{h}}, Z_{\mathrm{dr}}$, $K_{\mathrm{dp}}, \rho_{\mathrm{hv}}$, and SW at 0644 UTC. The dashed ellipses denote the graupel regions, and the dashed horizontal lines indicate the $-15^{\circ} \mathrm{C}$ isotherm.

This classification was performed based on the RHI scans presented in Fig. 6a (dendritic growth), Fig. 7a (aggregation), and Fig. 9a (riming) and the R-QVP profiles for the total event. The minimum and maximum values of $Z_{\mathrm{h}}$ have been identified for all heights separately (the vertically discretized heights in Fig. 6a were used for dendrites; similarly, the data presented in Figs. 7a and 9a were utilized for aggregates and rimed ice particles, respectively). The difference between $\max \left(Z_{\mathrm{h}}\right)$ and $\min \left(Z_{\mathrm{h}}\right)$ was calculated for each individual height and plotted in Fig. $14 \mathrm{a}\left(\Delta Z_{\mathrm{h}}\right)$. The $\Delta Z_{\mathrm{h}}$ values obtained from their respective RHI scans ranged from 10 to $17 \mathrm{~km}$ (the red rectangular boxes in 


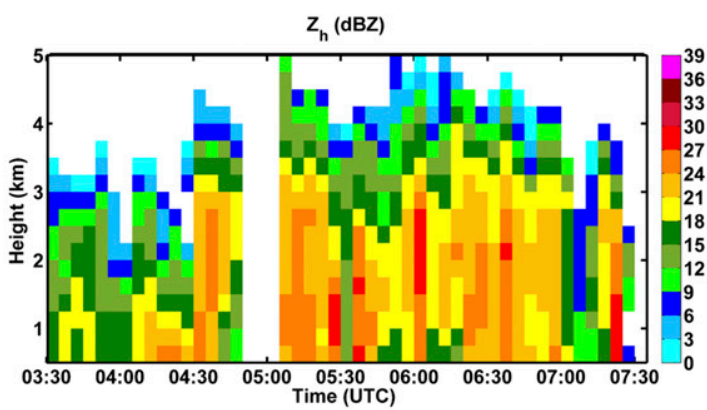

$\mathrm{z}_{\mathrm{dr}}(\mathrm{dB})$

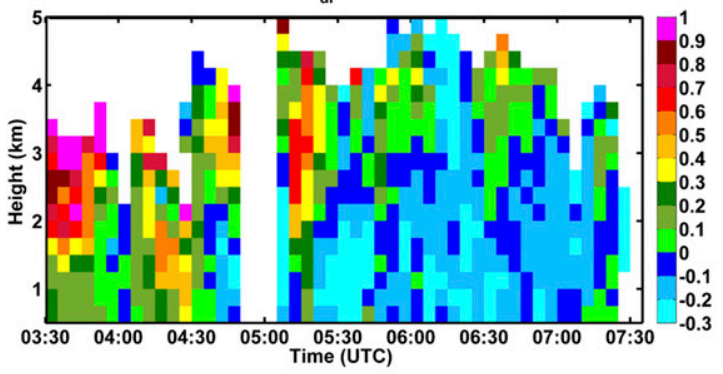

$\mathrm{K}_{\mathrm{dp}}\left(\mathrm{km}^{\mathrm{O}}\right)$

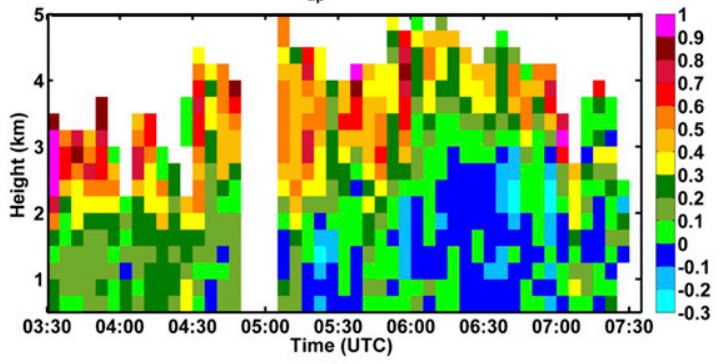

$\rho_{\mathrm{hv}}$
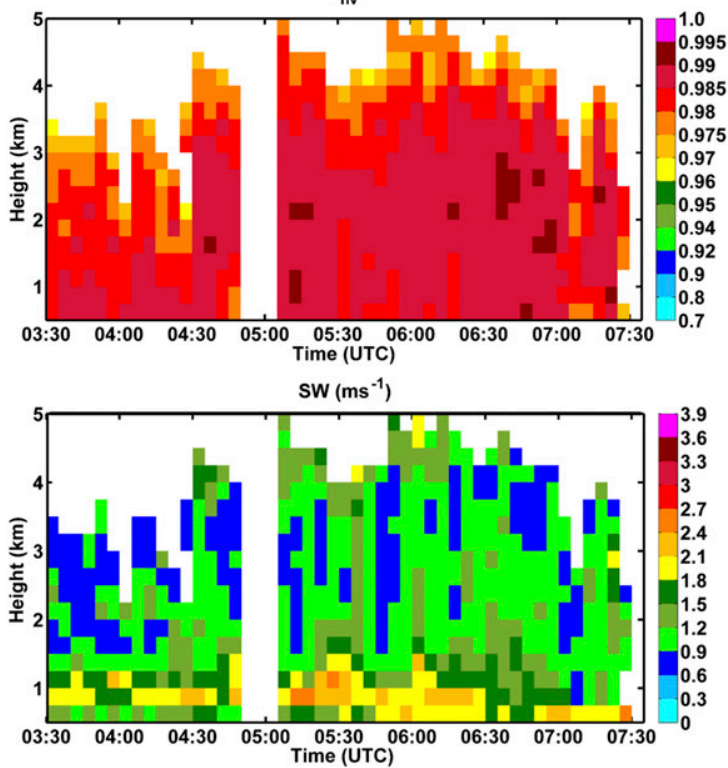

FIG. 13. R-QVP vertical profiles of (top to bottom) $Z_{\mathrm{h}}, Z_{\mathrm{dr}}, K_{\mathrm{dp}}$, $\rho_{\mathrm{hv}}$, and SW obtained for the entire snowfall event.
Fig. 6a), from 8 to $18 \mathrm{~km}$ (the red rectangular boxes in Fig. 7a), and from 5 to $15 \mathrm{~km}$ (the red rectangular boxes in Fig. 9a) for the dendritic growth, aggregation, and riming processes, respectively. If $\Delta Z_{\mathrm{h}}$ occupies a large range of values at low heights, it indicates riming. Similarly, if the range of $\Delta Z_{\mathrm{h}}$ is large at upper heights, particle aggregation occurs (Moisseev et al. 2009). Figure 14a shows that the riming process generates a greater range of $\Delta Z_{\mathrm{h}}$ at lower heights (below $2.5 \mathrm{~km}$ ) as compared to that obtained at upper heights (above $2.5 \mathrm{~km})$. In the case of dendrites and aggregates, the opposite is true $\left(\Delta Z_{\mathrm{h}}\right.$ is larger at upper heights as compared to that at lower heights). Interestingly, the $\Delta Z_{\mathrm{h}}$ range for aggregates (at upper heights) is slightly greater than that for dendrites. It is well known that dendrites are more oblate than aggregates. Furthermore, dendrites or platelike crystals are more anisotropic and produce mostly identical $Z_{\mathrm{h}}$ values with a smaller difference between $\max \left(Z_{\mathrm{h}}\right)$ and $\min \left(Z_{\mathrm{h}}\right)$. On the other hand, aggregates are formed when the branches of dendrites or platelike crystals interact with each other and become entwined. They exhibit higher variability of shapes and sizes and thus generate a broad range of $Z_{\mathrm{h}}$ values. Therefore, we speculate that the range of $\Delta Z_{\mathrm{h}}$ for dendrites is smaller than that for aggregates. However, the variance of $\Delta Z_{\mathrm{h}}$ for dendrites is smaller than for other particles. To demonstrate this classification feature, the R-QVP of SVZ (containing $\Delta Z_{\mathrm{h}}$ values obtained at all heights) is plotted for the entire event in Fig. 14b following the methodology illustrated in Fig. 2. It shows that $\Delta Z_{\mathrm{h}}$ is larger $(>12 \mathrm{dBZ})$ at upper heights (above $2.5 \mathrm{~km}$ ) than that at lower heights $(<12 \mathrm{~dB} Z)$ in the period from 0430 to 0515 UTC, indicating the presence of aggregates. On the other hand, from 0515 to $0700 \mathrm{UTC}$, the range of $\Delta Z_{\mathrm{h}}$ at lower heights is larger (mostly $\geq 20 \mathrm{~dB} Z$ ) than that obtained at upper heights (mostly $<20 \mathrm{~dB} Z$ ), indicating the presence of rimed ice particles. Furthermore, at upper heights the $\Delta Z_{\mathrm{h}}$ of aggregates (0430-0515 UTC) is slightly higher than the magnitude obtained for dendrites (0330-0430 UTC). Hence, it can be suggested that the range of $\Delta Z_{\mathrm{h}}$ may be used to identify the ice particle category and differentiate between the aggregates and rimed ice particles. We are currently in the process of investigating this phenomenon in more detail, and related data will be discussed in future works.

\section{Summary and conclusions}

In this study, the characteristics of the severe winter storm occurred over the Korean Peninsula were 
TABLE 3. Categories of various microphysical species and the corresponding values of the main parameters determined for the studied event.

\begin{tabular}{|c|c|c|c|c|c|c|}
\hline Category & $Z_{\mathrm{h}}(\mathrm{dB} Z)$ & $Z_{\mathrm{dr}}(\mathrm{dB})$ & $K_{\mathrm{dp}}\left({ }^{\circ} \mathrm{km}^{-1}\right)$ & $\rho_{\mathrm{hv}}$ & $\mathrm{SW}\left(\mathrm{m} \mathrm{s}^{-1}\right)$ & $T\left({ }^{\circ} \mathrm{C}\right)$ \\
\hline Dendrites & 10 to 30 & 0 to 1.4 & 0 to 2 & $\sim 0.98$ & 1 to 1.4 & $\sim-15$ \\
\hline Dendrites plus aggregate embryos & 15 to 30 & -0.3 to 1.4 & 0.4 to 1.1 & $\sim 0.98$ & 1 to 1.6 & $\sim-15$ \\
\hline Aggregates & 18 to 30 & -0.4 to 1.1 & -0.2 to 0.2 & $>0.98$ & 1 to 1.8 & $>-15$ \\
\hline Rimed ice crystals/rimed aggregates & 13 to 40 & -1.3 to 0.7 & -1 to 0.2 & $>0.98$ & 1 to 3 & $>-15$ \\
\hline
\end{tabular}

examined for the first time by the KICT X-band dualpolarization radar. A new R-QVP methodology for analyzing polarimetric radar variables was proposed to comprehensively describe the microphysical processes of ice particles as well as the evolution of the storm and snow growth processes in the spatial and temporal forms. The maximum values of $Z_{\mathrm{dr}}$ and $K_{\mathrm{dp}}$ (obtained at 0334 UTC) associated with a high $Z_{\mathrm{h}}$ gradient and depressed $\rho_{\mathrm{hv}}$ were obtained at a temperature of around $-15^{\circ} \mathrm{C}$, indicating the dendritic growth of crystals similar to that observed in previous studies (Kennedy and Rutledge 2011; Bechini et al. 2013; Andrić et al. 2013). Below the maxima of $Z_{\mathrm{dr}}$ and $K_{\mathrm{dp}}$, the magnitudes of $\mathrm{W}$ and $Z_{\mathrm{h}}$ increased toward the ground. The enhanced $Z_{\mathrm{dr}}$ values likely indicated the growth of planar crystals. The increase in $\mathrm{W}$ was observed exactly at the height $(\sim 2.6 \mathrm{~km})$ of high $K_{\mathrm{dp}}$ suggesting the start of the new ice particle growth. The offset between the maxima of $K_{\mathrm{dp}}$ and $Z_{\mathrm{dr}}$ likely resulted from the presence of early aggregates. Further, the

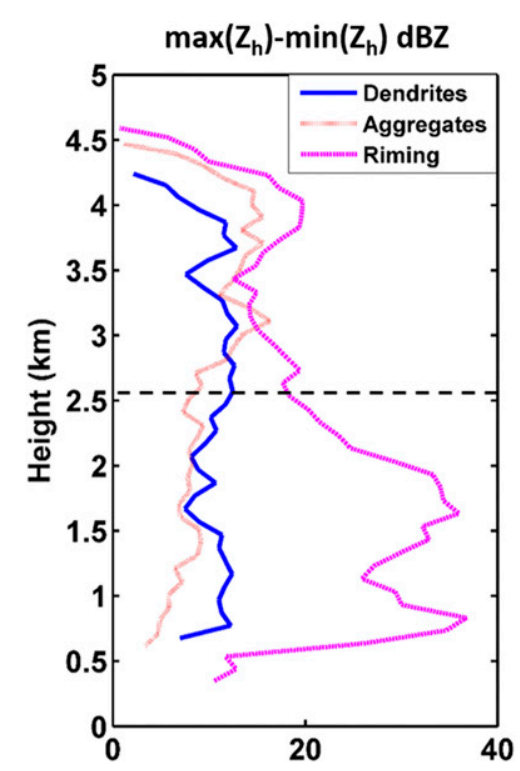

FIG. 14a. R-QVP vertical profiles of the differences between $\max \left(Z_{\mathrm{h}}\right)$ and $\min \left(Z_{\mathrm{h}}\right)$ obtained for the dendritic growth, aggregation, and riming processes. The horizontal dashed line indicates the $-15^{\circ} \mathrm{C}$ isotherm. combination of high $Z_{\mathrm{h}}$ and $\rho_{\mathrm{hv}}$ values with low $Z_{\mathrm{dr}}$ and $K_{\mathrm{dp}}$ magnitudes obtained at lower heights (below $2.5 \mathrm{~km})$ indicated the existence of large aggregates. The low $Z_{\mathrm{dr}}$ (close to $0 \mathrm{~dB}$ ) and high $\rho_{\mathrm{hv}}(>0.98)$ values suggest that the formed ice clusters/aggregates were isotropic and possessed low densities. At upper heights (above $2 \mathrm{~km}$ ), the enhanced $Z_{\mathrm{dr}}$ and $K_{\mathrm{dp}}$ signatures obtained from 0330 to 0515 UTC represent D-type crystals; while from 0515 to 0700 UTC, the high $K_{\mathrm{dp}}$ with moderate $Z_{\mathrm{dr}}$ values indicate the presence of I-type crystals [which were also observed by Schrom and Kumjian (2016) and Griffin et al. (2018)].

The riming phenomenon (observed at 0559 UTC) has been explored by examining the signatures containing high $Z_{\mathrm{h}}(>25 \mathrm{~dB} Z)$ and slightly negative $Z_{\mathrm{dr}}$ values combined with the high $\rho_{\mathrm{hv}}(>0.985)$ and low $K_{\mathrm{dp}}$ (near zero) magnitudes, which pertain to the local updraft. Both small ice crystals and dense aggregates act as targets for the riming process. During riming, the updraft or vertical motion lifts a larger LWC to upper heights; as a result, the higher number of SLW droplets freeze on the surface of small ice crystals and dense aggregates to produce rimed crystals/rimed aggregates and, ultimately, snowflakes or graupel. Near the end of the event, very interesting signatures of pronounced negative $Z_{\mathrm{dr}}(<-0.1)$ and $K_{\mathrm{dp}}(<0)$ values associated with high $Z_{\mathrm{h}}(>25 \mathrm{~dB} Z)$ and high $\rho_{\mathrm{hv}}(>0.985)$ magnitudes were obtained at lower heights, which signified the

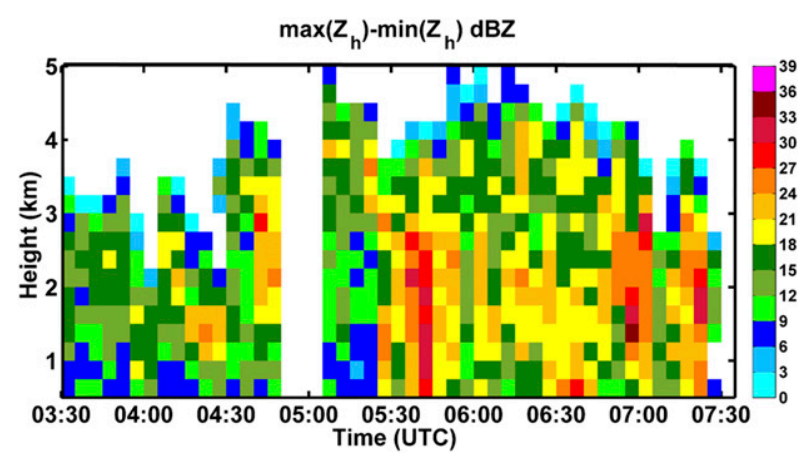

FIG. 14b. R-QVP of SVZ obtained for the entire snowfall event to classify different ice particle types. 
presence of graupel with conical and more complex shapes, as was also observed by Kouketsu et al. (2015) over Japan. Further, the high W values and ground observations confirm our interpretation. The classification of the obtained ice particles (aggregates, rimed snowflakes, and dendrites) was performed using the SVZ methodology. The R-QVP of SVZ was also utilized to distinguish between the aggregates and rimed ice particles. On the one hand, rimed ice covered a larger range of SVZ values at lower heights (as compared to that of aggregates). On the other hand, at upper heights, aggregates produced a larger range of $\Delta Z_{\mathrm{h}}$ leading to higher SVZ relative to dendrites. Further, as the dendritic growth mechanism changed to aggregation growth, $Z_{\mathrm{h}}$ increased, $Z_{\mathrm{dr}}$ decreased, $K_{\mathrm{dp}}$ decreased, and $\rho_{\mathrm{hv}}$ increased [similar to the phenomenon observed by Vogel et al. (2015)]. The riming process produced high $Z_{\mathrm{h}}$ with low $Z_{\mathrm{dr}}$ and $K_{\mathrm{dp}}$ values as compared to those obtained during the dendritic and aggregation growths. The observed polarimetric signatures of various snow growth processes were compared with the microphysical output of the WRF Model and verified by ground observations. After the detection of the enhanced $K_{\mathrm{dp}}-Z_{\mathrm{dr}}$ signatures at 0334 UTC, a heavy snowfall occurred on the ground about an hour later, at 0430 UTC. The beginning of the snowfall event exhibited high values of $Z_{\mathrm{h}}$ at lower heights (on the surface) for several hours, while the enhanced $K_{\mathrm{dp}}$ and $Z_{\mathrm{dr}}$ layers were linked to the heavy snowfall on the surface. The results obtained in this study can be used for the early warning of intense snowfall events and provide a foundation for the future studies aimed at investigating the finescale microphysics of winter storms occurring over this region in more detail.

Acknowledgments. This work was supported by the Korea Institute of Civil Engineering and Building Technology Strategic Research Project (Development of Driving Environment Observation, Prediction, and Safety Technology Based on Automotive Sensors). V. Chandrasekar was supported by the NASA GPM program.

\section{REFERENCES}

Andrić, J., M. R. Kumjian, D. S. Zrnić, J. M. Straka, and V. M. Melnikov, 2013: Polarimetric signatures above the melting layer in winter storms: An observational and modeling study. J. Appl. Meteor. Climatol., 52, 682-700, https://doi.org/ 10.1175/JAMC-D-12-028.1.

Aydin, K., and T. A. Seliga, 1984: Radar polarimetric backscattering properties of conical graupel. J. Atmos. Sci., 41, 18871892, https://doi.org/10.1175/1520-0469(1984)041<1887: $\mathrm{RPBPOC}>2.0 . \mathrm{CO} ; 2$.

Bechini, R., L. Baldini, and V. Chandrasekar, 2013: Polarimetric radar observations in the ice region of precipitating clouds at C-band and X-band radar frequencies. J. Appl. Meteor.
Climatol., 52, 1147-1169, https://doi.org/10.1175/JAMC-D-12055.1.

Bringi, V. N., and V. Chandrasekar, 2001: Polarimetric Doppler Weather Radar: Principles and Applications. Cambridge University Press, $636 \mathrm{pp}$.

—, P. C. Kennedy, G. J. Huang, C. Kleinkort, M. Thurai, and B. M. Notaroš, 2017: Dual-polarized radar and surface observations of a winter graupel shower with negative $Z_{\mathrm{dr}}$ column. J. Appl. Meteor. Climatol., 56, 455-470, https://doi.org/ 10.1175/JAMC-D-16-0197.1.

Carey, L. D., and S. A. Rutledge, 2000: The relationship between precipitation and lightning in tropical island convection: A C-band polarimetric radar study. Mon. Wea. Rev., 128, 2687-2710, https://doi.org/10.1175/1520-0493(2000)128<2687: TRBPAL $>2.0$.CO;2.

Chen, H., S. Lim, V. Chandrasekar, and B. J. Jang, 2017: Urban hydrological applications of dual-polarization X-band radar: Case study in Korea. J. Hydrol. Eng., 22, E5016001, https:// doi.org/10.1061/(ASCE)HE.1943-5584.0001421.

Chu, X., L. Xue, B. Geerts, and B. Kosovic, 2018: The impact of boundary layer turbulence on snow growth and precipitation: Idealized large eddy simulations. Atmos. Res., 204, 54-66, https://doi.org/10.1016/j.atmosres.2018.01.015.

Dolan, B., and S. A. Rutledge, 2009: A theory-based hydrometeor identification algorithm for X-band polarimetric radars. J. Atmos. Oceanic Technol., 26, 2071-2088, https://doi.org/ 10.1175/2009JTECHA1208.1.

Evaristo, R., T. Bals-Elsholz, E. Williams, A. J. Fenn, M. Donovan, and D. Smalley, 2013: Relationship of graupel shape to differential reflectivity: Theory and observations. 29th Conf. on Environmental Information Processing Technologies, Austin, TX, Amer. Meteor. Soc., 14, https://ams.confex.com/ams/ 93Annual/webprogram/Paper214462.html.

Garrett, T. J., E. H. Bair, C. J. Fallgatter, K. Shkurko, R. E. Davis, and D. Howlett, 2012: The multi-angle snowflake camera. Proc. Int. Snow Science Workshop, Anchorage, AK, International Snow Science Workshop, 930-933, http://arc.lib.montana.edu/ snow-science/item/1672.

Grazioli, J., G. Lloyd, L. Panziera, C. R. Hoyle, P. J. Connolly, J. Henneberger, and A. Berne, 2015: Polarimetric radar and in situ observations of riming and snowfall microphysics during CLACE 2014. Atmos. Chem. Phys., 15, 13787-13802, https://doi.org/10.5194/acp-15-13787-2015.

Griffin, E. M., T. J. Schuur, A. V. Ryzhkov, H. D. Reeves, and J. C Picca, 2014: A polarimetric and microphysical investigation of the Northeast blizzard of 8-9 February 2013. Wea. Forecasting, 29, 1271-1294, https://doi.org/10.1175/WAF-D-14-00056.1.

,-- , and -2018 : A polarimetric analysis of ice microphysical processes in snow, using quasi-vertical profiles. J. Appl. Meteor. Climatol., 57, 31-50, https://doi.org/10.1175/ JAMC-D-17-0033.1.

Hallett, J., and S. C. Mossop, 1974: Production of secondary ice particles during the riming process. Nature, 249, 26-28, https:// doi.org/10.1038/249026a0.

Homeyer, C. R., and M. R. Kumjian, 2015: Microphysical characteristics of overshooting convection from polarimetric radar observations. J. Atmos. Sci., 72, 870-891, https://doi.org/ 10.1175/JAS-D-13-0388.1.

Houze, R. A., Jr., 2014: Cloud Dynamics. Academic Press, 573 pp.

Juga, I., M. Hippi, D. Moisseev, and E. Saltikoff, 2012: Analysis of weather factors responsible for the traffic "Black Day" in Helsinki, Finland, on 17 March 2005. Meteor. Appl., 19, 1-9, https://doi.org/10.1002/met.238. 
Kennedy, P. C., and S. A. Rutledge, 2011: S-band dual-polarization radar observations of winter storms. J. Appl. Meteor. Climatol., 50, 844-858, https://doi.org/10.1175/2010JAMC2558.1.

Knight, C. A., and N. C. Knight, 1973: Conical graupel. J. Atmos. Sci., 30, 118-124, https://doi.org/10.1175/1520-0469(1973) $030<0118: \mathrm{CG}>2.0 . \mathrm{CO} ; 2$.

Kouketsu, T., and Coauthors, 2015: A hydrometeor classification method for X-band polarimetric radar: Construction and validation focusing on solid hydrometeors under moist environments. J. Atmos. Oceanic Technol., 32, 2052-2074, https:// doi.org/10.1175/JTECH-D-14-00124.1.

Kumjian, M. R., and K. A. Lombardo, 2017: Insights into the evolving microphysical and kinematic structure of northeastern U.S. winter storms from dual-polarization Doppler radar. Mon. Wea. Rev., 145, 1033-1061, https://doi.org/10.1175/ MWR-D-15-0451.1.

—, S. Mishra, S. E. Giangrande, T. Toto, A. V. Ryzhkov, and A. Bansemer, 2016: Polarimetric radar and aircraft observations of saggy bright bands during MC3E. J. Geophys. Res. Atmos., 121, 3584-3607, https://doi.org/10.1002/2015JD024446.

Lim, S., D. Moisseev, V. Chandrasekar, and D. R. Lee, 2013: Classification and quantification of snow based on spatial variability of radar reflectivity. J. Meteor. Soc. Japan, 91, 763 774, https://doi.org/10.2151/jmsj.2013-603.

List, R., and R. S. Schemenauer, 1971: Free-fall behavior of planar snow crystals, conical graupel and small hail. J. Atmos. Sci., 28, 110-115, https://doi.org/10.1175/1520-0469(1971)028<0110: FFBOPS $>2.0 . \mathrm{CO} ; 2$.

Locatelli, J. D., and P. V. Hobbs, 1974: Fall speeds and masses of solid precipitation particles. J. Geophys. Res., 79, 2185-2197, https://doi.org/10.1029/JC079i015p02185.

Magono, C., and C. W. Lee, 1966: Meteorological classification of natural snow crystals. J. Fac. Sci. Hokkaido Univ., 2, 321-335.

Michimoto, K., 1991: A study of radar echoes and their relation to lightning discharge of thunderclouds in the Hokuriku District. Part I: Observation and analysis of thunderclouds in summer and winter. J. Meteor. Soc. Japan, 69, 327-335, https://doi.org/ 10.2151/jmsj1965.69.3_327.

Min, K. H., S. Choo, D. Lee, and G. Lee, 2015: Evaluation of WRF cloud microphysics schemes using radar observations. Wea. Forecasting, 30, 1571-1589, https://doi.org/10.1175/WAF-D14-00095.1.

Moisseev, D., E. Saltikoff, and M. Leskinen, 2009: Dualpolarization weather radar observations of snow growth processes. 34th Conf. on Radar Meteorology, Williamsburg, VA, Amer. Meteor. Soc., 13B.2, http://ams.confex.com/ams/ pdfpapers/156123.pdf.

_ - S. Lautaportti, J. Tyynela, and S. Lim, 2015: Dual-polarization radar signatures in snowstorms: Role of snowflake aggregation. J. Geophys. Res. Atmos., 120, 12 644-12 655, https:// doi.org/10.1002/2015JD023884.

Oue, M., M. R. Kumjian, Y. Lu, J. Verlinde, K. Aydin, and E. E. Clothiaux, 2015: Linear depolarization ratios of columnar ice crystals in a deep precipitating system over the Arctic observed by zenith-pointing Ka-band Doppler radar. J. Appl. Meteor. Climatol., 54, 1060-1068, https://doi.org/10.1175/ JAMC-D-15-0012.1.
— M. Galletti, J. Verlinde, A. Ryzhkov, and Y. Lu, 2016: Use of $\mathrm{X}$-band differential reflectivity measurements to study shallow Arctic mixed-phase clouds. J. Appl. Meteor. Climatol., 55, 403-424, https://doi.org/10.1175/JAMC-D-15-0168.1.

Pruppacher, H. R., and J. D. Klett, 1997: Microphysics of Clouds and Precipitation. 2nd ed. Kluwer Academic, 954 pp.

Rienecker, M. M., and Coauthors, 2011: MERRA: NASA's Modern-Era Retrospective Analysis for Research and Applications. J. Climate, 24, 3624-3648, https://doi.org/10.1175/ JCLI-D-11-00015.1.

Ryzhkov, A., P. Zhang, H. Reeves, M. Kumjian, T. Tschallener, S. Trömel, and C. Simmer, 2016: Quasi-vertical profiles-A new way to look at polarimetric radar data. J. Atmos. Oceanic Technol., 33, 551-562, https://doi.org/10.1175/JTECH-D-150020.1.

Scarchilli, G., V. Gorgucci, V. Chandrasekar, and A. Dobaie, 1996: Self-consistency of polarization diversity measurement of rainfall. IEEE Trans. Geosci. Remote Sens., 34, 22-26, https:// doi.org/10.1109/36.481887.

Schneebeli, M., N. Dawes, M. Lehning, and A. Berne, 2013: Highresolution vertical profiles of X-band polarimetric radar observables during snowfall in the Swiss Alps. J. Appl. Meteor. Climatol., 52, 378-394, https://doi.org/10.1175/JAMC-D-12015.1.

Schönhuber, M., G. Lammer, and W. L. Randeu, 2008: The 2Dvideo-distrometer. Precipitation: Advances in Measurement, Estimation and Prediction, Springer, 3-31.

Schrom, R. S., and M. R. Kumjian, 2016: Connecting microphysical processes in Colorado winter storms with vertical profiles of radar observations. J. Appl. Meteor. Climatol., 55, 1771-1787, https://doi.org/10.1175/JAMC-D-15-0338.1.

,-- , and Y. Lu, 2015: Polarimetric radar signatures of dendritic growth zones within Colorado winter storms. J. Appl. Meteor. Climatol., 54, 2365-2388, https://doi.org/10.1175/ JAMC-D-15-0004.1.

Skamarock, W. C., and Coauthors, 2008: A description of the Advanced Research WRF version 3. NCAR Tech. Note NCAR/ TN-475+STR, 113 pp., https://doi.org/10.5065/D68S4MVH.

Vivekanandan, J., S. M. Ellis, R. Oye, A. V. Ryzhkov, and J. Straka, 1999: Cloud microphysics retrieval using S-band dual-polarization radar measurements. Bull. Amer. Meteor. Soc., 80, 381-388, https://doi.org/10.1175/1520-0477(1999) $080<0381$ :CMRUSB $>2.0$. CO; 2 .

Vogel, J., F. Fabry, and I. Zawadzki, 2015: Attempts to observe polarimetric signatures of riming in stratiform precipitation. 37th Conf. on Radar Meteorology, Norman, OK, Amer. Meteor. Soc., 6B.6, https://ams.confex.com/ams/37RADAR/ webprogram/Paper275246.html.

Wallace, J. M., and P. V. Hobbs, 2006: Atmospheric Science: An Introductory Survey. Elsevier, $504 \mathrm{pp}$.

Wang, Y., and V. Chandrasekar, 2009: Algorithm for estimation of the specific differential phase. J. Atmos. Oceanic Technol., 26, 2565-2578, https://doi.org/10.1175/2009JTECHA1358.1.

Wolde, M., and G. Vali, 2001: Polarimetric signatures from ice crystals observed at $95 \mathrm{GHz}$ in winter clouds. Part I: Dependence on crystal form. J. Atmos. Sci., 58, 828-841, https:// doi.org/10.1175/1520-0469(2001)058<0828:PSFICO >2.0.CO;2. 